Crops and Products

Elsevier Editorial system(tm) for Industrial

Manuscript Draft

Manuscript Number: INDCRO-D-18-03527R2

Title: European bamboo fibres for composites applications, study on the seasonal influence.

Article Type: Research Paper

Section/Category: Bio-based Materials from Crops

Keywords: Bamboo; Natural fibres; Composites; Seasonal effect; Mechanical properties; Chemical characterisation

Corresponding Author: Miss Delphine E. C. Depuydt,

Corresponding Author's Institution: KU Leuven Department of Materials Engineering, Campus Groep T, Andreas Vesaliusstraat 13, 3000 Leuven, Belgium

First Author: Delphine E. C. Depuydt

Order of Authors: Delphine E. C. Depuydt; Lawrence Billington; Carlos Fuentes; Nick Sweygers; Chirstine Dupont; Lise Appels; Jan Ivens; Aart W van Vuure

Abstract: Four Phyllostachys species grown in Europe were analysed with the aim of extracting long bamboo fibres for composite applications. The morphological characteristics of the plant were determined and compared to the species grown in their native region. Though the species tend to grow smaller, the Phyllostachys vivax showed similar Young's modulus as the tropical Guadua angustifolia Kunth, i.e. 49 GPa versus 52 GPa. But the strength of all species was 16 - 44 \% lower. A chemical analysis of the fibres and an interface study of their composites was performed by analysing the wetting behaviour of the fibres and the chemical composition of their surface. All fibres showed a lignin rich surface, with minor differences in wetting behaviour; therefore difference in the fibre mechanical properties cannot be explained by interface differences. The chemical bulk composition of the fibres was determined as well, and the cellulose content of the fibres showed a linear correlation with the Young's modulus and strength of the fibres. Seasonal investigation, performed on one selected species, revealed that harvest in autumn or winter lead to higher fibre extraction yields with higher mechanical properties. 
Dear Editor,

We wish to submit our research paper entitled "European bamboo fibres for composites applications, study on the seasonal influence. "

This manuscript has not been published elsewhere and is not under consideration by another journal. All authors have approved the manuscript and agree with its submission to Industrial Crops and Products.

In this paper bamboo grown in Europe is investigated for the first time with the aim of extracting long bamboo fibres for composite applications. This study has shown that Phyllostachys bamboo species grown in Europe, possess fibres with reasonable mechanical properties, and depending on the species even comparable Young's modulus as tropical species, though the strength of the fibres is somewhat lower. For species grown in Europe, the season of harvesting will also influence the properties of the fibres and harvest in autumn and winter is recommended.

We believe this is an interesting topic for Industrial Crops and Products.

Kind regards,

The authors 


\section{Detailed Response to Reviewers}

Dear Editor,

Following the feedback of the reviewer that was recieved after resubmission, an additional spelling check has been preformed before resubmitting the paper.

Thank you for the time and effort you have put in our work.

Delphine

Reviewer \#1: Dear author,

The feedback of the first review round and the regarding article editing was satisfying, 7correct, complete and fast. There are some very minor spelling issues, but not worth mentioning.

Congratuluations for a great article. Hope to read more about the topic in the future. 
Highlights (for review)

- European bamboo can have comparable fibre Young's modulus to tropical grown bamboo.

- The fibre strength is however lower ranging from $16-44 \%$ depending on the species.

- The season of harvesting will influence the properties of the fibres.

- Harvest in autumn and winter is recommended for optimal mechanical fibre properties 


\section{European bamboo fibres for composites applications, study on the seasonal influence.}

Delphine Depuydt ${ }^{\mathrm{a}}$, Lawrence Billington ${ }^{\mathrm{a}}$, Carlos Fuentes ${ }^{\mathrm{a}}$, Nick Sweygers $^{\mathrm{c}}$, Christine Dupont ${ }^{\mathrm{d}}$, Lise Appels $^{\mathrm{c}}$, Jan Ivens ${ }^{\mathrm{b}}$, Aart W. van Vuure ${ }^{\mathrm{a}}$

${ }^{a}$ KU Leuven, dept. Materials Engineering; Campus Groep T, Composite Materials Group, Andreas Vesaliusstraat 13, 3000 Leuven, Belgium

${ }^{\mathrm{b}}$ KU Leuven, dept. Materials Engineering; Campus De Nayer, Composite Materials Group, Jan De Nayerlaan 5, 2860 Sint-Katelijne-Waver, Belgium

${ }^{c}$ KU Leuven, dept. Chemical Engineering; Process and Environmental Technology Lab, Jan Pieter de Nayerlaan 5, 2860 Sint-Katelijne-Waver, Belgium

${ }^{\mathrm{d}}$ UCLouvain, Institute of Condensed Matter and Nanosciences, Place Louis Pasteur 1/L4.01.10, 1348 Louvain-la-Neuve, Belgium

Keywords: Bamboo; Natural fibres; Composites; Seasonal effect; Mechanical properties; Chemical characterisation

\section{Abstract}

Four Phyllostachys species grown in Europe were analysed with the aim of extracting long bamboo fibres for composite applications. The morphological characteristics of the plant were determined and compared to the species grown in their native region. Though the species tend to grow smaller, the Phyllostachys vivax showed similar Young's modulus as the tropical Guadua angustifolia Kunth, i.e. $49 \mathrm{GPa}$ versus $52 \mathrm{GPa}$. But the strength of all species was $16-44 \%$ lower. A chemical analysis of the fibres and an interface study of their composites was performed by analysing the wetting behaviour of the fibres and the chemical composition of their surface. All fibres showed a lignin rich surface, with minor differences in wetting behaviour; therefore difference in the fibre mechanical properties cannot be explained by interface differences. The chemical bulk composition of the fibres was determined as well, and the cellulose content of the fibres showed a linear correlation with the Young's modulus and strength of the fibres. Seasonal investigation, performed on one selected 
1 species, revealed that harvest in autumn or winter lead to higher fibre extraction yields with higher

2 mechanical properties.

\section{$3 \quad 1 \quad$ Introduction}

4

5 The grass family (Poaceae) consists of 12 subfamilies, with bamboo (subfamily Bambusoideae,

6 comprising both woody and herbaceous bamboos) being one of them. There are more than 1600

7 different bamboo species spread across the world and they are known to be native to Asia, Africa,

8 North- and, South-America and Oceania. The subfamily is divided into three tribes: Arundinarieae,

9 Bumbuseae and the Olyreae. The Arundinarieae tribe is the second largest, and comprises the

10 temperate woody bamboos, whereas the largest tribe is the Bambuseae containing the tropical woody

11 bamboos. The smallest tribe is the Olyreae or herbaceous bamboo. Unlike the other two tribes,

12 Olyreae do not have woody culms (Liese and Köhl, 2015). The Arundinarieae are made up out of 30

13 different genera amongst which the Phyllostachys is well known. The Phyllostachys pubescens also referred to as Phyllostachys edulis or Moso bamboo is considered as one of the most economically valuable bamboo species in the world (Dixon et al., 2015; Li et al., 2015). Above ground biomasses of 64 ton / ha are reported and this number could even increase when the plantations are managed and regularly harvested (Yiping et al., 2010). Moso is native of China but has been introduced in many other parts of the world such as Japan, Korea, Vietnam and Europe (Liese and Köhl, 2015).

More recently, as early as the first half of the $19^{\text {th }}$ century, mankind has been introducing bamboo species to Europe, mainly for the purpose of landscaping. Research has been conducted on the potential of European bamboo as energy crop for Europe (Gielis, 2000; Potters et al., 2009; Potters et al., 2013). Potters et al. (Potters et al., 2013) mentioned that three bamboo genera were considered suitable for the use in the European climate, the Sasa, Fargesia and Phyllostachys, amongst which the Phyllostachys has the highest biomass potential, and was chosen to further investigate. Several species were planted in Ireland by Potters et al. (Potters et al., 2009) and the ton dry weight per hectare was extrapolated from the measurements on the field, ranging between $5-18$ ton / ha. The research 
1 indicated that bamboo can grow in Europe (though it grows slower) and has comparable or higher

2 calorific value than other wood species. Compared to willow, Miscanthus and poplar, bamboo showed

3 a higher return on investment after 30 years. The feasibility of mechanical harvesting was also

4 investigated and strip harvesting was pointed out as promising. This is a rotation system in which

5 every third year the same strip is cut again. Harvesting was advised between October and March,

6 since mechanical harvesters (for corn, or sugar cane) are normally not used during these months

7 (Gielis, 2000).

8

9 Bamboo has a very unique exterior appearance. Long segmented stems, called culms, are visible

10 above the ground along with branches and leaves towards the top of the plant. The culm grows from a

11 highly branched underground shoot-root network, called the rhizome system. The culm is made up of numerous joints, called nodes, with hollow internodes connecting them. The hollow internodes are separated by diaphragms at each node. Long unidirectional (UD) fibres run within the culm wall of the internodes and are discontinued at the nodes. These fibres are of special interest for the composite industry since they can serve as a natural fibre reinforcement. Interest in the use of bamboo reinforced composites is shown by recent work of (Gu et al., 2018; Kalali et al., 2019; Zhang et al., 2019). Since bamboo is not native to Europe, most of the bamboo species investigated originate from the continents where it is native. However, in this research, the morphology of bamboo grown in Europe is characterised and the mechanical properties of the fibres are assessed.

Bamboo culms appear in many different sizes, depending on their species and environmental conditions. Culm lengths can vary significantly between species. Some grow as small as $0.5 \mathrm{~m}$, while other species can easily grow over $30 \mathrm{~m}$ tall, with some species even growing up to $40 \mathrm{~m}$ (Liese and Köhl, 2015). Not only the total length of the plant can vary, also the length of the internodes, the outer diameter of the plant and the wall thickness vary along the bamboo culm. Amada et al. (Amada et al., 1997) investigated the variation of the internodal length along the culm for the Phyllostachys edulis Riv. for culms of two years old though the origin is not specified in the paper, probably cultivated in Japan. At the base of the culm (bottom segment), the internodes are short, with basal internodal 
1 lengths around $10-25 \mathrm{~cm}$. From the base, the internodal length increases towards the middle segment

2 of the culm where the internodes reach a maximum length, up to $40 \mathrm{~cm}$. The work of Banik (Banik,

3 2015) showed that different internodal length variations for different bamboo species can be found.

4 The internodal lengths is important as it determines the maximum length of the fibres that can be

5

6 extracted.

Not only the internodal lengths are of importance, also the diameters and wall thickness along the culm dictate the volume of extractable fibres. Generally, culm outer diameters and wall thicknesses are largest near the base of the culm, and decrease towards the top. From the work of Amada et al. (Amada et al., 1997) the decrease appears to be rather constant from about internode 10 onwards. Between internodes 10 and 50 the outer diameter decrease and wall thickness decrease are approximately 2.6 and $0.2 \mathrm{~mm}$ per internode respectively. Diameter at breast height (DBH), is measured $1.3 \mathrm{~m}$ aboveground and is a method of expressing the diameter of the stem (culm) to allow an easy comparison, since their diameters vary with height (Liese and Köhl, 2015). Culm outer diameters at breast height have been documented to vary between 5 and $30 \mathrm{~cm}$, depending on the species (Kuehl, 2015).

Figure 1 shows the exploded view of the hierarchical structure of a bamboo plant. The culm wall is made up of numerous vascular bundles surrounded by parenchyma cells. Parenchyma cells are the filler material which makes up the ground tissue, and help to give bamboo its stability and flexibility (Liese, 1998; Parameswaran and Liese, 1976). Each vascular bundle contains the conducting tissue (phloem, protoxylem, metaxylem) surrounded by sclerenchyma cells. These are referred to as the fibre sheaths or strands if they are isolated (Liese and Köhl, 2015). During the extraction of bamboo fibres, these regions get separated from the parenchyma tissue. The extracted fibre has the length of the internode and a diameter between $90-280 \mu \mathrm{m}$ and is a bundle of fibrous cells, called technical fibre. A technical fibre can be a full fibre sheath, but it can also be a part of a fibre sheath that is broken up into multiple technical fibres. The mechanical properties of technical bamboo fibres can be found in Table 1 of Depuydt and Hendrickx et al. (Depuydt et al., 2017), Young's moduli of $52 \pm 7$ 
$1 \mathrm{GPa}$, and strengths of $658 \pm 135 \mathrm{MPa}$ have been recorded for the Guadua angustifolia Kunth species.

2 Each technical fibre is built up out of many fibrous cells, called elementary fibres. Elementary fibres

3 are characterised by their honeycomb structure, held together by a fine layer of lignin matrix, with

4 typical lengths and diameters of $1-4.3 \mathrm{~mm}$ and $10-40 \mu \mathrm{m}$ respectively (Liese, 1998; Liese and Köhl,

$52015)$

$6 \quad$ [insert Figure 1]

7 The three main building blocks of bamboo plants are: cellulose, hemicellulose and lignin; with 8 cellulose being the main responsible for the strength and stiffness of the plant. The cellulose forms 9 crystalline microfibrils that are arranged in a helical configuration within the cell wall. The angle that 10 is formed with the fibre axis is called the microfibril angle (MFA). According to the model of 11 Parameswaran and Liese (Parameswaran and Liese, 1976), the cell wall of the elementary fibre is built up out of several layers, with more layers being deposited when the plant grows older, leading to thickening of the cell wall. This process is also referred to as maturisation or lignification.

As a fourth component in the living plant, water should be mentioned. Living plants are optimised to function with a relatively high amount of water in them. This moisture content varies with the age of the plant, the species, the location of growth, but also with the position of the fibre within the culm. Moisture contents have been reported to vary along the culm length and across the culm wall, with higher moisture contents at the base of the culm and at the inner part. For a 3 - 4 year old Dendrocalamus strictus culm, the base had $100 \%$ moisture whereas the top contained only contained $60 \%$ (Liese, 1985). Liese and Grover (Liese W. und Grover P. N., 1961) showed the influence of the type of cells present in the culm, i.e. the parenchyma amount is linearly related to the water uptake. It is generally accepted that the moisture content plays an important role in the ease of extraction of the technical fibres used for composites.

Yet the most important external factor influencing the moisture content of the culm is the season, in (sub)tropical climates a minimum was found at the end of the dry period, followed by a maximum reached in the rainy season (Liese, 1985). Van Goethem et al. (Van Goethem, 2013) studied the 
1 moisture content of four Phyllostachys species grown in Ireland. It was found that the total biomass of

2 all species contained $1 / 3$ up to $1 / 2$ less moisture in spring compared to summer. The higher moisture

3 content in summer was attributed to the seasonal variation in biomass distribution, with more leaf

4 material present in summer compared to spring. This resulted in a higher water content. The ideal

5 harvesting time is also concluded to be autumn or winter, though for a different consideration, namely

6 the low starch content of the plant in this time of year, which is linked with biological degradation due

7 to beetle attack or fungal deterioration (Van Goethem, 2013). Furthermore the research revealed that

8 during this period, the free glucose amount is low in the above ground biomass, and harvesting at that

9 time, leaves more reserves for the plant. Also during the winter season the plant sap flow rates, are

10 minimal, and therefore the loss of plant sap and nutrients through cut culms is minimal.

When the bamboo dries, shrinkage occurs. Unlike wood, bamboo shrinks also above the fibre saturation point. Bamboo shows the highest shrinkage in radial direction, and the smallest in axial direction. Latif and Liese (Latif and Liese, 1995) reported for the Malaysian bamboo species Gigantochloa levis which contained $30-77 \%$ moisture, a radial shrinkage of $5-14 \%$ and a tangential shrinkage of $2-10 \%$. This is confirmed by the work of Azadeh et al. (Azadeh and Ghavami, 2018) where it was found that shrinkage in the tangential direction is $30-50 \%$ less than the radial direction. In the same research, the effect of heat treatment on bamboo was investigated and it was shown that heating the bamboo up to $225{ }^{\circ} \mathrm{C}$ can reduce water absorption up to $15 \%$. In the work of Anokye et al. (Anokye et al., 2014) it was found that the radial shrinkage was slightly greater than tangential shrinkage though the difference was much smaller, and not significant. Additionally the shrinkage was found to be inversely proportional to the moisture content of the bamboo culm.

In this research the mechanical properties of fibres extracted by a purely mechanical process from different European bamboo species are investigated, as well as the seasonal influence on them. To further characterise the species, a chemical analysis and an interface study of their composites is performed by analysing the wetting behaviour of the fibres and the chemical composition of their surface. 
22 Materials and Methods

$3 \quad 2.1 \quad$ Species and harvesting

4 In this research four Asian bamboo species, grown in Europe, of the Phyllostachys genus are studied:

5 Phyllostachys nigra Boryana (PNB), Phyllostachys aureosulcata Spectabilis (PAS), Phyllostachys

6 vivax (PV) and, Phyllostachys vivax McClure Jiantonging (PVMJ). The PNB originates from Japan

7 and has been reported to grow on average $15 \mathrm{~m}$ in height and $7.5 \mathrm{~cm}$ in diameter, characterised by

8 green internodes with purplish-black blotches (Ohrnberger, 1996). The PAS has been documented to

9 grow culms ranging from 5 to $9 \mathrm{~m}$ in height with outer diameters between 2 and $5 \mathrm{~cm}$. This species

10 naturally grows in China and was introduced to Europe in the late $19^{\text {th }}$ century for landscaping

11 (Ohrnberger, 1996). When compared to the PAS, the PV species grow larger culms. The PV is native

12 to China and can grow more than $21 \mathrm{~m}$ in height and $15 \mathrm{~cm}$ in diameter, though it is rather thin-walled

13 (Meredith, 2010). The PVMJ seems to be an undocumented wild type, but the Phyllostachys vivax

14 McClure is native to China and has been reported to grow culms ranging from 10 to $15 \mathrm{~m}$, with

15 maximum heights of $21 \mathrm{~m}$, and diameters ranging from 4 to $8 \mathrm{~cm}$, with maximum diameters up to 13

$16 \mathrm{~cm}$ (Ohrnberger, 1996).

European bamboo was harvested from the botanical garden (arboretum) and the tree nursery in the Provincial domain of Bokrijk (Belgium). This region is characterised by a temperate climate, an altitude of $47 \mathrm{~m}$, an annual temperature of $9.8{ }^{\circ} \mathrm{C}$ and an year average relative humidity of $80 \%$. The selected species were chosen based on their seize and estimated yield. It is known that the age of the plantation influences the dimensions of the bamboo, with newly planted plantations yielding smaller plants. In this research all 'plantations' were planted long time ago (more than 6 years ago) and are therefore mature (Liese and Köhl, 2015). Plantation maturity is different from the culm maturity, common accepted to be 2-3 years (Liese and Köhl, 2015). Culm maturity is linked with the lignification of the plant, which has an influence on the mechanical properties; maximum strength is reached after 2-3 years. Previous study (Depuydt et al., 2019) compared technical bamboo fibres of 
1 different age and concluded that the fibres can be considered ready for harvest after 1 year, since the maximum mechanical properties were reached.

4 The new shoots, of the considered species, appeared in the month of April, and were marked in the year 2015, after a few months of growth. Only marked culms were harvested, therefore the exact age of all the culms is known in this research. In the beginning of the Autumn of 2016, after approximately a year and a half of growing, tree culms of each species were harvested. This was done by sawing the culms near the ground, without extracting any of the rhizomes from the soil. The

9 branches and the leaves were cut off and collected separately in order to determine the total biomass

10 of each culm. The culm internodes were numbered from bottom to top, to allow further 11 characterisation. The PNB the PAS were harvested the $15^{\text {th }}$ of September 2016 , the PV the $28^{\text {th }}$ of September 2016 and the PVMJ the $12^{\text {th }}$ of October 2016.

Weather and climate data published by the Royal Meteorological Institute (RMI) of Belgium were used to study the climate conditions prior to harvesting.

\subsection{Morphological characterisation and fibre extraction}

17 Morphological measurements of the culms were done during the week of harvesting, before any major 18 size reductions occurred, due to the effect of moisture loss. The length (between the middle of points of the enclosing nodes) and the outer diameter (at the middle of the internode) were measured for each internode along the whole culm. The culm wall thickness was also determined at the middle of the internode for every 5 internodes. For the diameter and wall thickness measurements a calliper was used, for the length a tape measure.

The internodal length will determine the maximum fibre length of the extracted fibres. Long fibres are desired to make unidirectional composites with homogeneously oriented fibres; shorter fibres are more difficult to align. The thickness of the culm will influence the total amount of fibres that can be extracted. Because of these two reasons, only certain internodes with minimum length and wall 
1 thickness will be suitable for fibre extraction on an industrial scale for the purpose of UD composite

2 production. To avoid having to cut through each internode and reducing the fibre length by half, in

3 order to determine the thickness in the middle of the internode, the outer diameters were measured

4 instead to evaluate the internode's potential extraction volume. In this research the minimum

5 internodal length and outer diameter were chosen to be $25 \mathrm{~cm}$ and $3 \mathrm{~cm}$ respectively, to evaluate the

6 fraction of the culm suitable for fibre extraction on an industrial scale. All internodes which met both

7 criteria were located in the middle of the culm (classified as the middle segment). Internodal numbers

8 below and above the middle were classified as bottom and top segments respectively.

9

10 Fibres were extracted via a purely mechanical procedure, developed at KU Leuven (Osorio et al.,

11 2011), which is for confidentiality reasons not disclosed. For each culm internodes 11 and 16 were used to extract the fibres from, since these two internode numbers lie always inside the middle segment range. Fibre extraction was performed in the same week of harvest. Standard in the preparation method of Guadua angustifolia Kunth fibres (Osorio et al., 2011; Perremans et al., 2018), a cleaning step is performed, involving brushing the fibres with the addition of water to remove residual parenchyma. However, for these European fibres, this step was not performed, since trials showed that no parenchyma was removed in this manner. Therefore the fibres were immediately dried after extraction for at least one week at $60{ }^{\circ} \mathrm{C}$ before producing composites.

\subsection{Moisture and biomass content}

All weight determinations of the fresh plant were performed the day of harvest. The above ground part of the harvested bamboo was separated in two parts, the first one being the culm and the second one the branches and leaves. The fresh bamboo plant contains moisture which contributes to the weight of the plant, this is the wet weight $\left(\mathrm{m}_{\text {wet }}\right)$. The remaining culm pieces of internode 11 and 16 , from the fibre extraction, were selected for the determination of the culm moisture content. From the 3 different culms, minimum 12 samples in total were used (wet weight around $10-20 \mathrm{~g}$ ) for moisture determination and were therefore dried for at least $24 \mathrm{~h}$ at $105^{\circ} \mathrm{C}$. This weight is referred to as the dry weight $\left(\mathrm{m}_{\text {dry }}\right)$. The moisture content was determined via Eq. 1 . This moisture content, based on these 
1 two internodes, is considered as the average moisture content in the middle segment of the culm. The

2 leaves and branches were dried in their entirety in a bigger oven at the same temperature for the same

3 amount of time, to determine their dry weight as well.

4

$5 \quad M C \%=\frac{\mathrm{m}_{w e t}-m_{d r y}}{m_{w e t}} * 100 \%$

\section{$6 \quad 2.4 \quad$ Microscopy and areal fibre bundle fraction determination}

7 Radial sections of $1 \mathrm{~cm}$ in width were cut out of the $15^{\text {th }}$ internode for each of the bamboo species and 8 embedded in an EpoxiCure 2 epoxy mounting resin and EpoxiCure 2 hardener from Buehler. The 9 samples were sanded and polished and analysed with a light microscope (Axioskop 40, Zeiss) to study 10 the areal fibre bundle fraction. The microscopic images (300 dpi) were processed with image $\mathrm{J}$ by applying a threshold filter which separated the fibre bundles from the surrounding parenchyma. By

12 dividing the area occupied by fibre bundles by the total culm cross section, the areal fibre bundle

13 fraction was determined. This value represents the maximum achievable fibre extraction percentage.

\section{$14 \quad 2.5$ Density of the bamboo fibres}

15 In order to calculate the volume fraction of the fibres in the composite, based on their weight, the 16 density of the extracted fibres needs to be known. Therefore gas pycnometer measurements were 17 performed using a Quantachrome multi pycnometer model MVP-D160-E with helium gas at a pressure of 1.5 bar as displacement medium. The fibres were dried prior to milling for 1 week in an oven at $60{ }^{\circ} \mathrm{C}$. Milling was performed with a centrifugal mill, type Retsch ZM100 (Gemini BV, Netherlands), which reduced the bamboo particles size to values smaller than $250 \mu \mathrm{m}$. The fibre dust was dried in a vacuum oven for at least 5 hours at $30^{\circ} \mathrm{C}$ before measuring.

\subsection{Impregnated fibre bundle test} Impregnated fibre bundle (IFBT) tests were prepared as described by Bensadoun et al. (Bensadoun et al., 2017). Unidirectional composites were made and the stiffness and strength were back calculated from the composite properties via the rule of mixtures. The IFBT gives a direct measurement of the 
1 average fibre properties. The bamboo fibres were dried for at least one week at $60^{\circ} \mathrm{C}$ prior to

2 production and weighing. Epikote 828 LVEL epoxy with a 1,2-diaminocyclohexane (Dytek DCH-99)

3 hardener from Hexion was used as matrix, mixing ratio 100:15.2. Curing was done at $75^{\circ} \mathrm{C}$ for 1 hour

4 followed by a subsequent post cure of 1 hour at $150^{\circ} \mathrm{C}$. Composites of $150 \times 7.5 \times 0.9 \mathrm{~mm}$ were made

5 with a target volume fraction of $40 \%$ fibres. The exact volume fraction per composite was calculated

6 via Eq. 2, by dividing the utilized fibre bundle mass ( $\left.\mathrm{m}_{\mathfrak{r}}\right)$ by the respective fibre density $\left(\rho_{\mathrm{f}}\right)$ obtained

7 by gas pycnometer to obtain the total fibre volume, which is divided by the dimensions of the 8 composite (length $l$, width $w$, thickness $t$ ).

9

$10 \quad V_{f}=\frac{\frac{m_{f b}}{\rho_{f}}}{(l \times w \times t)}$

12 Tensile tests were performed according to the ASTM D3039 standard on an Instron 4467 tensile

13 testing machine with a $5 \mathrm{kN}$ load cell and a crosshead displacement of $2 \mathrm{~mm} / \mathrm{min}$. The specimens

14 were gripped with pneumatic grips at 6 bars. The specimen gauge length was $7 \mathrm{~cm}$ and an

15 extensometer of $2.5 \mathrm{~cm}$ was used to measure the strain of the specimens. Eight specimens were tested

16 per species. The Young's modulus was calculated as the tangent of the stress-strain curve between

$17 \quad 0.1-0.3 \%$ strain. To compare multiple group means, a two sided Analysis of Variance (ANOVA) is performed $(\alpha=0.05)$ with a Tukey HSD test, to reveal which groups are significantly different from

19 each other.

$20 \quad 2.7$ Seasonal study

21 The influence of the seasons was studied for the Phyllostachys nigra Boryana species, since this

22 species was pointed out to be most hardy by the plantation caretakers. During one year, bamboo

23 culms were harvested in each season from 15/09/2016 to 3/10/2017, from shoots sprouted in April

24 2015. At each harvest, 3 culms were taken for analysis. In July, two times bamboo culms were

25 harvested to study the sensibility to the climate right before harvesting. Morphological 
1 characterisation, determination of moisture content and biomass and determination of the mechanical

2 properties of the fibres by IFBT, were performed as described above.

4 The extraction yield at each moment of harvest was determined, averaged over the two internodes that were selected for fibre extraction. The yield is calculated according to Eq. 3 .

6

$7 \quad$ Fibre extraction yield $\%=\frac{\text { weight extracted fibres }}{\text { wet }} * 100 \%$

9 Additionally the shrinkage of the harvested bamboo culms was assessed. In order to do so, small 10 specimens of $20 \times 4 \times \mathrm{tmm}$ were milled from the middle of the $15^{\text {th }}$ internode of the fresh culm, with $\mathrm{t}$ 11 representing the thickness of the culm wall. This operation was performed within the same day of 12 harvesting. Three samples per culm, leading to a total of 9 samples were analysed in this way. The cut samples were immediately weighed and measured before drying for $24 \mathrm{~h}$ at $105^{\circ} \mathrm{C}$. The length, width and thickness of the samples was measured at 3 points before and after drying. The maximum shrinkage coefficient was calculated as by Eq. 4, with $\mathrm{X}$ representing the analysed dimension, being either the length, width or thickness of the sample. Figure 2 shows the direction of the radial, tangential and longitudinal shrinkage.

19 Maximum shrinkage coefficient $X \%=\frac{X_{\text {wet }}-X_{\text {dry }}}{X_{\text {wet }}} * 100 \%$ [insert Figure 2]

\subsection{Fibre bulk chemical characterisation}

To determine the chemical composition, i.e. the lignin, cellulose and hemicellulose content, an adapted Van Soest method developed by Sweygers et al. (Sweygers et al., 2018) was used. Fibres were milled to powder in the same way as described for the gas pycnometer measurements. In a first step, a neutral detergent at $100{ }^{\circ} \mathrm{C}$ was applied, thereby extracting the digestible cell contents (soluble sugars, starch) while the hemicellulose, cellulose and lignin fractions remain. In a second step, the 
1 residual content was treated with sodium chlorite and acetic acid at $75^{\circ} \mathrm{C}$ in a water bath, the loss in

2 matter is attributed to the lignin fraction. The remaining fraction, being the holocellulose, is treated

3 with a mildly acidified detergent at $100{ }^{\circ} \mathrm{C}$, which only leaves cellulose as the sole particulate matter.

4 The ash content is determined by heating the fibre particles for $2 \mathrm{~h}$ at $550{ }^{\circ} \mathrm{C}$ in a muffle furnace. The

5 residual inorganic matter is the ash content. The cellulose, hemicellulose and lignin percentages

6 mentioned in this report were determined by subtracting the ash content and extractives from the

7 batch, and rescaling the former components to $100 \%$. The measurements were performed in threefold

8 each measurement requiring $1 \mathrm{~g}$ of material. The mean chemical composition of the species are

9 compared and analysed via an ANOVA test $(\alpha=0.05)$.

$10 \quad 2.9 \quad$ X-ray photoelectron spectroscopy (XPS) analysis

11 The technical bamboo fibres were cleaned in hot water $\left(90{ }^{\circ} \mathrm{C}\right)$ for 1 hour following the procedure

12 proposed by Fuentes et al. (Fuentes et al., 2011). XPS-analysis was performed on the 4 species to

13 determine the chemical components on their surface. These analyses were performed on a Kratos Axis

14 Ultra spectrometer (Kratos Analytical, Manchester, UK) equipped with a monochromatised aluminium X-ray source (powered at $10 \mathrm{~mA}$ and $15 \mathrm{kV}$ ) by the Surface Characterisation platform at the Institute of Condensed Matter and Nanosciences (IMCN) in Louvain-La-Neuve. The analysed area was $700 \mu \mathrm{m} \times 300 \mu \mathrm{m}$, with the longest dimension aligned with the length of the fibre. Full description of the XPS-analysis method is given in (Fuentes et al., 2011).

\subsection{Wetting behaviour}

Advancing contact angles of ultrapure water $(18.2 \mathrm{M} \Omega \mathrm{cm}$ resistivity, $72.8 \mathrm{mN} / \mathrm{m}$ surface tension) were measured on bamboo fibres at room temperature $\left(20{ }^{\circ} \mathrm{C}\right)$ and relative humidity of $50 \%$, using a Krüss K100 SF tensiometer equipped for the Wilhelmy technique with a resolution of $0.1 \mu \mathrm{g}$. This technique consists in measuring the forces exerted by a liquid on a solid substrate with known perimeter while the substrate is vertically and partially immersed into the test liquid and then withdrawn (Fuentes et al., 2011). Four smooth fibres were randomly selected from each species harvested between 15/09/2016 and 12/10/2016, and were cleaned using the same procedure as the 
1 fibres prepared for the XPS analysis. Afterwards they were wiped with ethanol and dried in an oven at

$260{ }^{\circ} \mathrm{C}$ for at least 1 day before contact angle measurements.

4 The fibre is immersed into the liquid and the microbalance measures a force ( $\left.F_{\text {measured }}\right)$, which is the sum of the capillary force $\left(F_{\text {wetting }}\right)$, the weight of the fibre $(G)$ and the buoyancy force $\left(F_{\text {buoyancy }}\right)$ :

$F_{\text {measured }}=F_{\text {wetting }}+G-F_{\text {buoyancy }}=p \gamma \cos \theta_{V}+m g-\pi \rho g r^{2} h$

9 Where $p$ is the fibre perimeter, $r$ is the fibre radius (assuming the fibre to be a perfect circular cylinder), $\gamma$ the liquid surface tension, $m$ the fibre mass, $g$ the acceleration of gravity, $\rho$ the liquid density and $h$ the immersion depth. When the weight of the probe is measured beforehand and set to zero on the balance, only the wetting and buoyancy forces remain:

$F_{\text {measured }}=2 \pi r \gamma \cos \theta_{V}-\pi \rho g r^{2} h$

All dynamic contact angle measurements were conducted at a velocity of $1.5 \mathrm{~mm} / \mathrm{min}$ and with a 0.01 $\mathrm{mm}$ data sampling step over a fibre length of $6 \mathrm{~mm}$. The average and standard deviation values reported in this study were calculated from the data obtained for a given length portion of a fibre; so e.g. for a $1 \mathrm{~mm}$ length portion of the fibre, this means that 100 data-points were averaged.

The method applied to determine the fibre perimeter is based on the same principle as the Wilhelmy technique. In this case, however, the perimeter is sought. When a liquid with $0^{\circ}$ contact angle is used and buoyancy is neglected, the Wilhelmy Eq. 6, becomes:

At relatively low speeds, very low surface tension hexane is assumed to have a contact angle of $0^{\circ}$ with virtually all substrates (Fuentes et al., 2011). 
1 Since the Wilhelmy method is based on measuring the wetting force, the liquid absorbed by the fibre

2 can distort contact angle measurements. Liquids may penetrate the structure of natural fibres as well,

3 modifying the force value and so the calculated dynamic contact angle. However, Fuentes et al.

4 (Fuentes et al., 2011) evaluated the effect of sorption during the Wilhelmy experiments on bamboo

5 fibres, by measuring the difference between the weight of the fibre before immersion, and the weight

6 of the fibre after it was removed at a velocity of $1,5 \mathrm{~mm} / \mathrm{min}$. They concluded that the effect of weight

7 of water absorbed and adsorbed is small and does not significantly alter contact angle measurements

8 on bamboo fibres. Another phenomenon occurring, when the fibres are submerged in the fluid, is

9 diffusion of liquid molecules. During the advancing wetting experiments, Fuentes et al. (Fuentes et

10 al., 2011), have shown that this effect is limited since the contact line is continuously moving, as the

11 fibre moves through the fluid, resulting in only a small increment of fibre weight. Group mean

12 differences are analysed via an ANOVA test $(\alpha=0.05)$.

143 Results and Discussion

$15 \quad 3.1 \quad$ Physical properties of the culms

16 The four considered bamboo species show several different morphological characteristics. The 17 measured size and total weight of the fresh plant is summarized in Table 1 . An average height of $8 \mathrm{~m}$ and diameter of $4 \mathrm{~cm}$ is observed for the PNB; the height and diameter is only $53 \%$ of what is mentioned in literature (Ohrnberger, 1996). The observed culm height ( 7 m) and diameter at breast height $(\mathrm{DBH} \sim 4 \mathrm{~cm}$ ) of the bamboo species PAS is similar to the data found in literature (Ohrnberger, 1996), suggesting that this species has no difficulty growing in a European climate. PV reaches an average height of $12 \mathrm{~m}$ and diameter of $7 \mathrm{~cm}$, where the height reaches $57 \%$ and the diameter $46 \%$ of the value mentioned in literature (Meredith, 2010). PVMJ shows an average culm height of $10 \mathrm{~m}$ and diameter of $6 \mathrm{~cm}$. Both dimensions fall within the reported values in literature for the species grown in their native climate (Ohrnberger, 1996). From the analysis of the morphology of the plant it seems that the PNB and PV species are remarkably smaller compared to plants grown in their native climate. 
2 From the four considered species grown in Europe PV and PVMJ are the largest, and PNB and PAS

3 seem to be relatively short and possess thin culm walls. When comparing PV and PVMJ, they do not seem to differ much in size; their noticeable difference lies in their weight (culm, branches and leaves). Of the four studied bamboo species, the Phyllostachys vivax (PV) appears to be the tallest

6 with the largest weight.

7 The middle section of the plant suited for fibre extraction meets two criteria, i.e. the internodal length is $>25 \mathrm{~cm}$ and the outer diameter of the culm internode is $>3 \mathrm{~cm}$. In this way the middle section is separated from the basal and top section. Figure 3 shows the internodal length along the culm as function of the serial number of the internode for each species. Species PV and PVMJ have similar, larger elongated middle segments with 1.5-2.4 times more internodes being longer than $25 \mathrm{~cm}$ compared to PAS and PNB. For all species considered, at the top section of the plant, the outer diameter drops below $3 \mathrm{~cm}$ before the intermodal length becomes smaller than $25 \mathrm{~cm}$. The outer diameters along the culm length, shown in Figure 4, are significantly lower for species PNB and PAS, further limiting the amount of internodes suitable for fibre extraction $(>3 \mathrm{~cm})$ to only 13 and 10 respectively. [insert Figure 3 and 4]

The average internodal length, outer diameter, wall thickness and number of internodes suitable for extraction, is given in Table 2, and appears to be the highest for PV, indicating that this species shows the most potential for the purpose of bamboo fibre production on an industrial scale. Though the average moisture content of the culm and areal growth density of the species should be taken into account before making final conclusion of the biomass yield. [insert Table 2]

When analysing the wall thickness of the plant, highest wall thicknesses can be found near the basal area of the culm and it decreases towards the top. Some remarkable behaviour can be seen when looking at the wall thickness as function of the internodal diameter as can be seen in Figure 5. There appears to be a linear correlation between both, starting from internodal numbers greater than 10 
1 where the linearity continues up to the top internodes (25-35). This behaviour occurs for each species

2 and shows the possibility of quickly and simply estimating the wall thicknesses along bamboo culms by measuring the outer diameter, without having to make cuts or use other more complex, expensive tools. Table 3 shows the coefficients for the linear region of each bamboo species. [insert Figure 5] [insert Table 3]

\subsection{Biomass and moisture content}

The fresh weight fractions and moisture content data of the bamboo culms are shown in Figure 6. Figure 6a shows the weight dominance of the PV and PNB. Though the PNB species was not the largest in culm size, a high amount of branches and leaves leads to a total fresh weight of around $8 \mathrm{~kg}$ equal to the PV. For PNB, the culm accounts for $5 \mathrm{~kg}$ of the above ground weight and for PV $6 \mathrm{~kg}$. For all four species, the culms made up between 60 - $80 \mathrm{wt} \%$ of the total above ground weight and had moisture contents, as seen in Figure 6b, between 40 and 51 wt $\%$, whilst the moisture content of the branches and leaves was slightly higher between $50-54 \mathrm{wt} \%$. Subtracting the moisture content from the branches and leaves and the culm, leads to a total biomass of $4.4 \mathrm{~kg}, 1.3 \mathrm{~kg}, 4.4 \mathrm{~kg}$ and 2.5 $\mathrm{kg}$ of the PNB, PAS, PV and PVMJ respectively.

\section{[Insert Figure 6]}

The weight distribution along the culm was $13-26,63-80,5-28$ wt\% respectively for the bottom, middle and top segment (shown in Figure 6c). For species PV and PVMJ almost 80 wt\% of the culms' weight is suitable for fibre extraction (internodal length $>25 \mathrm{~cm}$, diameter $>3 \mathrm{~cm}$ ). PNB and PAS showed only $64 \mathrm{wt} \%$ of the culm suitable for fibre extraction. Based on these results the PV and PNB show the most potential, as these species culms' weight is $1.5-3$ times more than the other two species, of the PV even $80 \%$ of the culm is suitable for the extraction of long technical fibres. To make final decisions, the culm areal growth densities have to be determined as well in order to evaluate the biomass yield of a plantation. Density of bamboo fibres and areal fibre bundle fraction Table 4 shows the measured fibre densities $\left(\rho_{\mathrm{f}}\right)$, which range between $1.43-1.48 \mathrm{~g} / \mathrm{cm}^{3}$ for all four species considered. The difference between the species is considered low (maximum $3 \%$ ) and the 
1 obtained values are similar to other densities found in literature (Depuydt et al., 2019). The areal fibre

2 bundle fractions are also given in Table 4 and were determined from the cross sectional images via the

3 process shown in Figure 7a-b. Within this part of the culm the fibre bundle areal density which

4 equates to the volume fraction of fibres, is about $27 \%$ for all species.

$5 \quad$ [insert Table 4]

$6 \quad$ [insert Figure 7]

7 Figure 7a shows the culms' cross section for all four bamboo species. The PV cross-section has many

8 large cracks running through the technical fibres. These cracks run through the lignin which bonds the

9 elementary fibres together. The other species also show some cracks, but these are not as frequent and

10 smaller in width. All the samples were prepared in the same way, and no reason for this difference is

11 known to the authors. Therefore it is assumed a characteristic of this species.

When observing the PAS culm's cross sections in more detail, it was noticed that the outer region had many fibres containing holes, as seen in Figure 8. These holes seem to be filled with parenchyma cells and can be relatively large compared to the fibre bundle itself. If these fibres do not break up during extraction of the fibres, the parenchyma will remain enclosed by the fibre. Because the fibre cross sectional area is determined by means of weighing, the extra parenchyma will lead to an overestimation of the fibre weight resulting in an underestimation of the mechanical properties (Young's modulus and strength), however in this case this effect is judged to be small, since only a

20 few fibres show these enclosed parenchyma cells.

$21 \quad$ [insert Figure 8]

\section{$22 \quad 3.3 \quad$ Impregnated fibre bundle tests}

23 Bamboo fibre reinforced composites were prepared with fibres extracted from internode 11 and 16

24 which lie for all species in the middle segment, suitable for fibre extraction. Composites were manufactured with an epoxy resin as matrix and subjected to longitudinal tensile tests. The IFBT tests were done on 8 specimens containing mixed fibres of both internodes. The actual fibre volume fraction $\left(\mathrm{V}_{\mathrm{f}}\right)$ of the specimens was calculated using Eq. 2. 
2 The composite properties and back calculated fibre properties are given in Figure 9 for the PNB, PAS,

3 PV and PVMJ species. The PNB was also selected for the seasonal investigation, since this species was pointed out most hardy by the plantation caretakers, and is further elaborated in section 3.5. For the fibre Young's modulus values between 37 - $49 \mathrm{GPa}$ are found, and for the strength values between $371-551 \mathrm{MPa}$ with an average strain to failure of $\sim 1 \%$. An ANOVA analysis was performed $(\alpha=$ 0.05) to determine whether the differences between the species are significant. The PNB species shows a significantly lower Young's modulus whereas the PV species shows a significantly higher Young's modulus of $49 \pm 3 \mathrm{GPa}$. For the strength, the PNB species is significantly lower than PV and PVMJ and for the strain to failure, no significant differences could be found between the species.

11 [insert Figure 9]

12 Comparing these values to typical values found for tropical bamboo species, e.g. Guadua angustifolia Kunth, which has a Young's modulus of $52 \pm 7 \mathrm{GPa}$, strength of $658 \pm 135 \mathrm{MPa}$ and strain to failure of $1.3 \pm 0.2 \%$ (Depuydt et al., 2017), it can be stated that the Young's modulus seems less affected than the strength when comparing the tropical Guadua with the temperate Phyllostachys species considered in this research. The Young's modulus of the Phyllostachys is $6-29 \%$ lower, while the strength is $16-44 \%$ lower. These results are in agreement with another study performed (Depuydt et al., 2019), where the lower strength could be linked to a smaller length over diameter ratio of the elementary fibres of the Phyllostachys species.

\subsection{Seasonal study}

Figure 10 shows the back calculated mechanical properties of the PNB species, studied throughout the different seasons. An ANOVA analysis $(\alpha=0.05)$ reveals that September ' 16 and January ' 17 have a significantly higher Young's modulus than all the other times of harvest. The strength seems to follow a similar trend with higher properties for autumn and winter harvest, though the difference is only significant between January and July. 
1 To analyse the results further, the moisture content and the maximum shrinkage coefficient of the

2 bamboo culm was measured as well as the extraction yield (via Eq. 3) of fibres per harvest, as shown

3 in Figure 11. The moisture content and extraction yield seem to be related linearly to the mechanical

4 properties. It seems that the higher the moisture content, the higher the extraction yield, the higher the

5 Young's modulus and strength that was found. It is not surprising that the extraction of fibres is

6 facilitated with higher culm moisture contents, since water is known to act as a plasticiser and can in

7 this way help to separate the fibres from the surrounding parenchyma, without causing unwanted

8 fractures. Previous research [25] has shown that extracting fibres from a rewetted culm is more

9 difficult and leads to lower mechanical properties. Additional research on the difference in culm

10 structure between a rewetted and fresh culm would still be interesting.

11 [insert Figure 11]

12 Extraction yields vary between $10-16 \%$ by weight. Assuming a fibre density of $1.4 \mathrm{~g} / \mathrm{cm}^{3}$ and a density of $0.65 \mathrm{~g} / \mathrm{cm}^{3}$ for the rest material (including, parenchyma, remaining fibres and outer skin) (Liese and Köhl, 2015), this represents $5-8$ volume percent. This value can be compared with the areal fibre bundle fraction obtained in section 3.3, varying between 26 - 28 volume percent. From these values it is seen that $18-30 \%$ of the fibres present in the culm, can be extracted. From experience it is known that the fibres close to the outer skin are more difficult to extract. Therefore, the extraction yield is expected to increase if the culm wall becomes thicker, as the fraction of skin to the total cross section is reduced.

Figure 12 shows the moisture content in the culm as function of the precipitation averaged over 5 days prior to harvesting (Royal Meteorological Institute (RMI), Accessed in 2016-2017). No clear relation between the culm moisture content and the precipitation could be found, neither between the average amount of sunlight 5 days before harvesting and the culm moisture content. Instead the explanation that the moisture content in the culm is higher in the autumn and winter season is rather sought in the fact that the evapotranspiration processes stop when the climate becomes colder. Thus, preparing for the winter rest, the culm stores more moisture. 
1 Figure 11 also gives insight in the shrinkage behaviour of the culm, determined via Eq. 4. Throughout

2 the seasons the radial shrinkage varies between $5.9-7.4 \%$, which is $1.7-2.7$ times bigger than the

3 tangential shrinkage which varies between $2.7-4.4 \%$. This is in agreement with literature, where the

4 average radial shrinkage is 1.6 times bigger than the average tangential shrinkage for the Malaysian

5 Gigantochloa levis species (Latif and Liese, 1995). Tangential and radial swelling occurs by water

6 that pushes the cellulose fibrils in the amorphous regions apart and the hemicellulose. The

7 longitudinal shrinkage is almost negligible, since water cannot easily penetrate in longitudinal

8 direction between cellulose material of high crystallinity, so on drying also little water will be

9 expelled. The crystalline microfibrils are thus largely insensitive to moisture; values of longitudinal

10 shrinkage between $0.07-0.56 \%$ were found. In the tangential shrinkage a few significant differences

11 were found considering the different seasons. The tangential shrinkage in April '17 was larger compared to September '16 and October '17, also January '17 showed higher shrinkage than October

'17. For the radial shrinkage no seasonal dependence could be determined. Although a relationship between the moisture content and the volumetric shrinkage (sum of the radial, tangential and longitudinal shrinkage) was expected, this was not found in this research. When shrinkage takes place cell collapse can occur; this phenomena was not studied, but could be interesting to investigate throughout the seasons.

This seasonal harvesting leads to the conclusion that autumn and winter are the preferred seasons to harvest bamboo culms grown in an European climate, to increase the yield and most likely reduce the damage to the fibres during extraction. This coincides with other arguments for autumn/winter harvest that are mentioned in literature, like the availability of harvesting equipment and a low starch content which lowers the risk of beetle attack (Gielis, 2000; Van Goethem, 2013).

\subsection{Fibre bulk chemical composition}

Table 5 gives the results of the chemical characterisation of the different species considered. The cellulose content of all species varies between $51-55 \%$, the hemicellulose between $12-16 \%$ and the lignin between $31-36 \%$. These values for the European species are comparable to the chemical 
1 composition of the 1 - 3 year old Guadua angustifolia Kunth (GAK), measured in previous research

2 (Depuydt et al., 2019). Though it is seen that the ash content and especially the extractives content are

3 much higher for the European species. The difference in extractives content can be found in the

4 method of preparing the fibres. In this research, the European fibres were not brushed with the

5 addition of water as is standard practice for the GAK fibres. A cleaning step involving water, can

6 remove the extractives present in de the plant.

$7 \quad$ [insert Table 5]

8

9 Highly oriented crystalline cellulose is the main responsible for the strength and stiffness of the fibres,

10 an ANOVA analysis $(\alpha=0.05)$ revealed that the PV has significantly higher and the PNB and PAS

11 significantly lower cellulose content than the other species considered. In this research the cellulose

12 content is in correlation with the measured mechanical properties, i.e. the fibres Young's modulus and

13 the strength.

\subsection{XPS measurement}

The relative surface atomic fractions, $\mathrm{O} / \mathrm{C}$ ratio and decomposition of $\mathrm{C} 1 \mathrm{~s}$ peaks obtained by XPS for the 4 different species are given in Table 6. Different functional groups contribute to the shape of the $\mathrm{C} 1$ s spectrum of lignocellulosic materials. $\mathrm{C} 1$ represents the $\mathrm{C}-(\mathrm{C}, \mathrm{H})$ linkages of mainly lignin (Shchukarev et al., 2002) and extractives; $\mathrm{C} 2$ the $\mathrm{C}-\mathrm{OH}$ groups of cellulose, hemicelluloses, lignin and extractives as well as $\mathrm{C}-\mathrm{O}-\mathrm{C}$ linkages of lignin and extractives. $\mathrm{C} 3$ contains the $\mathrm{C}=\mathrm{O}$ bonds in lignin and the extractives, as well as O-C-O linkages in cellulose and hemicellulose; whilst C4 contains the $\mathrm{COOH}$ groups of hemicelluloses as well as the $\mathrm{COOC}$ and $\mathrm{COOH}$ groups of the extractives (Fuentes et al., 2014). As reported by Johansson (Johansson et al., 1999), cellulose is ideally devoid of aliphatic carbon-carbon bonds (designated as C1), while in milled wood lignin, 49\% of the carbon atoms are $\mathrm{C} 1$ type. Then the relative concentration of the $\mathrm{C} 1$ component can be used to determine the presence of lignin on the fibre surface. 
1 Looking at the deconvoluted C1s peak, given in Table 6, all four species appear to have a similar

2 surface chemical composition. Although PVMJ fibre showed a relatively lower amount of $\mathrm{C} 1$ carbon

3 type (43\%); the other species showed a $\mathrm{C} 1$ type in a range between 46 to $56 \%$. These values are far

4 from the reference for cellulose $(0 \%)$ and closer to the reference for milled wood lignin $(49 \%)$.

5

6 Lignin content on the fibre surface can also be evaluated by determining the oxygen-to-carbon atomic ratio $(\mathrm{O} / \mathrm{C})$, reported to be within $24-41 \%$ for lignin and $83 \%$ for cellulose (Fuentes et al., 2011; Johansson et al., 1999; Shchukarev et al., 2002). Also the O/C ratio of the PVMJ species is different

9 from the other ones, reaching the highest value of $45 \%$, in comparison to a range between $34 \%$ to 38

$10 \%$ for the other 3 species. However, all $\mathrm{O} / \mathrm{C}$ values are far from cellulose, and within the range of 11 lignin.

Table 6 shows the comparison with XPS data found for the Gaudua angustifolia Kunth fibres (Fuentes et al., 2014) and Figure 13 maps the $\mathrm{C} 1$ component and $\mathrm{O} / \mathrm{C}$ ratio of the different species considered and some literature values (Fuentes et al., 2014; Fuentes et al., 2011; Johansson et al., 1999). The theoretical values for cellulose $(\mathrm{O} / \mathrm{C}=83, \mathrm{C} 1 / \mathrm{C}=0)$ and lignin $(\mathrm{O} / \mathrm{C}=33, \mathrm{C} 1 / \mathrm{C}=49)$ [29], have been omitted from the graph for clarity. Both indicators, the relative concentration of the $\mathrm{C} 1$ component and the oxygen-to-carbon atomic ratio $(\mathrm{O} / \mathrm{C})$, show a similar trend; i.e. the surface composition of all different bamboo fibre species are close to our references for lignin, indicating that the surface of technical bamboo fibres may be homogeneously covered with lignin and possibly some other molecules, but not with cellulose. Since the spectra are enriched in C1 links more than expected for milled wood lignin, the presence of other compounds such as lipids cannot be excluded. [insert Figure 13]

Comparing the XPS data, which show that mainly lignin is present on the surface, and the chemical composition, where it was shown that the bulk of the fibre consists out of $50 \%$ cellulose and only 30 $\%$ lignin, it is clear that the lignin is more concentrated towards the surface of the fibre. This is in agreement with the work of Lin et al. (Lin et al., 2002) where it was shown that lignin is the main 
1 component of the interlamella, surrounding the elementary fibres, and is therefore also highly present

2 at the surface of a technical fibre.

$3 \quad 3.7 \quad$ Wetting behaviour

4 The advancing contact angles of the fibres are given in Table 7. An ANOVA analysis $(\alpha=0.05)$

5 indicated no significant difference between the contact angles of the fibres of the four studied bamboo

6 species.

$7 \quad$ [insert Table 7]

8 From the XPS analysis it was shown that the surface of the bamboo fibres is mainly covered by lignin

9 and the advancing contact angles obtained in this research for PNB and PVMJ were $65 \pm 7^{\circ}$ and $67 \pm$

$108^{\circ}$ respectively, corresponding well with contact angles for water on lignin reported in literature (67 ${ }^{\circ}$

11 in (Liukkonen, 1997) and $69^{\circ}$ in (Fuentes et al., 2011)). Other major constituents of bamboo, like

12 cellulose and hemicellulose have been reported to have much lower contact angles of $14^{\circ}$ and $30^{\circ}$

13 respectively (Hodgson and Berg, 1988; Toussaint and Luner, 1993).

On the other hand, the average contact angles for PAS and PV were $78 \pm 11^{\circ}$ and $79 \pm 9^{\circ}$ respectively, which are higher than the values reported in literature for water on lignin mentioned in the paragraph above. Thus, the wetting behaviour of bamboo might be influenced by a combination of waxes, fatty substances and lignin. Particularly for PAS and PV the higher proportion of $\mathrm{C} 1$ carbon suggests a combination of hydrophobic hydrocarbon rich waxes and lignin (Kazayawoko et al., 1999).

Fuentes et al. (Fuentes et al., 2011) studied the wetting behaviour of technical bamboo fibres of the Guadua angustifolia Kunth, comparing non-treated fibres to autoclave-treated $\left(150{ }^{\circ} \mathrm{C}, 3\right.$ bars pressure) fibres; these results are given in Table 5. The non-treated bamboo fibres showed contact angles varying from $69^{\circ}$ up to $101^{\circ}$ with an average contact angle of $88 \pm 15^{\circ}$, showing large fluctuations due to a combined effect of surface irregularities (waviness and roughness) (Fuentes et al., 2011). Since the autoclave treatment smoothens the surface and reduces surface irregularities, the contact angle of treated fibres showed lower fluctuations, varying from $66^{\circ}$ up to $72^{\circ}$, with an 
1 average contact angle of $69 \pm 3{ }^{\circ}$. In this study the average contact angles, for the different species, vary between $65^{\circ}$ and $79^{\circ}$, which lies closer to the values found for the smooth autoclave-treated fibres. This might indicate a less rough surface inherent to the European extracted fibres.

If all the contact angles are compared together, there is no significant statistical difference (ANOVA analysis with $\alpha=0.05$ ). This might indicate that their interfacial characteristics do not explain the difference in the measured mechanical properties.

\section{Conclusions}

European bamboo was studied for the first time with the focus on extracting technical bamboo fibres for composite applications. Four species from the Phyllostachys genus were considered. The species were harvested between 15/09 and 12/10 of the year 2016 and their morphology was characterised. From the considered species the Phyllostachys nigra Boryana (PNB) and the Phyllostachys vivax (PV) grew significantly smaller than the dimensions of these species recorded in their native region. Still the Phyllostachys vivax showed to be the tallest species with a height of $11.7 \pm 1.2 \mathrm{~m}$, a diameter at breast height of $7.4 \pm 0.8 \mathrm{~cm}$ and a basal wall thickness of $10.7 \pm 1.9 \mathrm{~mm}$. Depending on the species considered, the internodes suited for fibre extraction varied between 10 and 25 pieces, with the latter corresponding to the Phyllostachys vivax. For all the species a linear relationship could be found between the wall thickness and the outer diameter, starting from internode 10 to the top of the plant.

The moisture content of the plants was measured, and the average moisture content of the culm varied between $40-51 \%$, whilst for the branches and leaves a variation between $50-54 \%$ was found. Taking this moisture content into account the biomass can be calculated per species per culm and is found to be highest for the PNB and PV species, both around $\sim 4.5 \mathrm{~kg}$, though the PNB has around the double weight of branches and leaves. This leads to less culm mass available for fibre extraction. 
2 The fibres from the 4 species were extracted and only small variations in the fibre density (maximum $33 \%$ ) could be found. Also cross sectional analysis of the culm wall, showed that the areal fibre bundle 4 fractions did not vary a lot between the species, with values between $25-28 \%$.

6 Impregnated fibre bundle tests, enabled the determination of the mechanical properties of the bamboo 7 fibres. Young's modulus values between 37 - $49 \mathrm{GPa}$, strength values between 371 - $551 \mathrm{MPa}$, and an 8 average strain to failure of $\sim 1 \%$ were found, with the PV showing the highest mechanical properties. 9 Comparing these values with the tropical Guadua angustifolia Kunth, it is seen that the Young's 10 modulus is less reduced than the strength. This is in agreement with previous research, where the 11 lower strength of the Phyllostachys species was linked to a smaller length over diameter ratio of the elementary fibres (Depuydt et al., 2019).

The XPS study showed that the fibre surface of all species is rich in lignin, with minor variations reflected in the contact angle measurements. However, in general, the contact angles were found largely similar for all considered species indicating that their interfacial characteristics cannot explain the difference in the measured mechanical properties. A chemical composition study, showed however that the mechanical properties are related to their chemical composition, i.e. the cellulose content. The more cellulose present, the higher the performance of the fibres, this link was not seen in previous bamboo fibre research (Depuydt et al., 2019).

For the seasonal investigation, the PNB species was chosen, as it was indicated as most hardy by the plantation caretakers. This study showed that the higher the moisture content, the higher the extraction yield of fibres and the higher the Young's modulus and strength of the fibres. The presence of water in the culm helps to facilitate the extraction of the fibres, by enabling easy separation from the surrounding parenchyma, without damaging the fibres. The water content in the culm was highest in autumn and winter. 
1 This study has shown that Phyllostachys bamboo species grown in Europe, possess fibres with

reasonable mechanical properties, and depending on the species even comparable Young's modulus as tropical species, though the strength of the fibres is somewhat lower. For species grown in Europe, the season of harvesting will also influence the properties of the fibres and harvest in autumn and winter is recommended.

Acknowledgements

The authors would like to thank Stijn Van Hoof for his help with the wetting experiments as well as Pierre Eloy from UC Louvain for his help with the XPS measurements. We would also like to acknowledge the financial support of the Impulse Fund KU Leuven (BOF/IMP14/034).

\section{References}

Amada, S., Ichikawa, Y., Munekata, T., Nagase, Y., Shimizu, H., 1997. Fiber texture and mechanical graded structure of bamboo. Compos. Part B: Engineering 28, 13-20.

Anokye, R., Kalong, R.M., Bakar, E.S., Ratnasingam, J., Jawaid, M., Awang, K., 2014. Variations in Moisture Content Affect the Shrinkage of Gigantochloa scortechinii and Bambusa vulgaris at Different Heights of the Bamboo Culm. Bioresour. 9, 7484-7493.

Azadeh, A., Ghavami, K., 2018. The influence of heat on shrinkage and water absorption of Dendrocalamus giganteus bamboo as a functionally graded material. Constr. Build. Mater. 186, 145154.

Banik, R.L., 2015. Morphology and Growth, Bamboo the Plant and its Uses. Springer International Publishing Switzerland pp. 43-91.

Bensadoun, F., Verpoest, I., Baets, J., Müssig, J., Graupner, N., Davies, P., Gomina, M., Kervoelen, A., Baley, C., 2017. Impregnated fibre bundle test for natural fibres used in composites. J. Reinf. Plast. Compos., 0731684417695461.

Depuydt, D., Hendrickx, K., Biesmans, W., Ivens, J., Van Vuure, A.W., 2017. Digital image correlation as a strain measurement technique for fibre tensile tests. Compos. Part A: Appl. Sci. Manuf. 99, 76-83.

Depuydt, D., Sweygers, N., Appels, L., Ivens, J., Van Vuure, A., 2019. Bamboo fibres sourced from 3 global locations, a microstructural, mechanical and chemical composition study. Accepted J. Reinf. Plast. Compos. 
1 Dixon, P.G., Ahvenainen, P., Aijazi, A.N., Chen, S.H., Lin, S., Augusciak, P.K., Borrega, M., 2 Svedstrom, K., Gibson, L.J., 2015. Comparison of the structure and flexural properties of Moso, 3 Guadua and Tre Gai bamboo. Constr. Build. Mater. 90, 11-17.

4 Fuentes, C.A., Beckers, K., Pfeiffer, H., Tran, L.Q.N., Dupont-Gillain, C., Verpoest, I., Van Vuure, 5 A.W., 2014. Equilibrium contact angle measurements of natural fibers by an acoustic vibration 6 technique. Colloids Surf, A.: Physicochem. Eng. Asp. 455, 164-173.

7 Fuentes, C.A., Tran, L.Q.N., Dupont-Gillain, C., Vanderlinden, W., De Feyter, S., Van Vuure, A.W., 8 Verpoest, I., 2011. Wetting behaviour and surface properties of technical bamboo fibres. Colloids 9 Surf, A.: Physicochem. Eng. Asp 380, 89-99.

10 Gielis, J., 2000. Future possibilities for bamboo in European agriculture. Oprins Plant, 2000, 11 Rijkevorsel, Belgium, Short report "Bamboo for Europe Project".

12 Gu, F., Zheng, Y.T., Zhang, W., Yao, X., Pan, D., Wong, A.S.M., Guo, J.F., Hall, P., Sharmin, N.,

Hodgson, K.T., Berg, J.C., 1988. Dynamic wettability properties of single wood pulp fibers and their 2018. Can bamboo fibres be an alternative to flax fibres as materials for plastic reinforcement? A comparative life cycle study on polypropylene/flax/bamboo laminates. Ind. Crops Prod. 121, 372-387.

Johansson, L.-S., Campbell, J.M., Koljonen, K., Stenius, P., 1999. Evaluation of surface lignin on cellulose fibers with XPS. Appl. Surf. Sci. 144-145, 92-95.

Kalali, E.N., Hu, Y., Wang, X., Song, L., Xing, W., 2019. Highly-aligned cellulose fibers reinforced epoxy composites derived from bulk natural bamboo. Ind. Crops Prod. 129, 434-439.

Kazayawoko, M., Balatinecz, J.J., Sodhi, R.N.S., 1999. X-ray photoelectron spectroscopy of maleated polypropylene treated wood fibers in a high-intensity thermokinetic mixer. Wood Sci. Technol. 33, 359-372.

Kuehl, Y., 2015. Resources, Yield, and Volume of Bamboos, Bamboo the Plant and its Uses. Springer International Publishing Switzerland pp. 92-111.

Latif, A.M., Liese, W., 1995. Utilization of bamboo, in: Razak, A.O., Latif, A.M., Liese, W., Norini, H. (Eds.), Planting and utilization of bamboo in Peninsular Malaysia. FRIM research pamphlet no. 118. Forest Research Institute Malaysia, Kuala Lumpur, Malaysia, pp. 50-102.

Li, P.H., Zhou, G.M., Du, H.Q., Lu, D.S., Mo, L.F., Xu, X.J., Shi, Y.J., Zhou, Y.F., 2015. Current and potential carbon stocks in Moso bamboo forests in China. J. Environ. Manage. 156, 89-96.

Liese, W., 1985. Anatomy and Properties of Bamboo, International Bamboo Workshop (INBAR), October 6-14 China.

Liese, W., 1998. The Anatomy of Bamboo Culms. International Network for Bamboo and Rattan.

Liese, W., Köhl, M., 2015. Bamboo The plant and its uses. Springer International Publishing Switzerland

Liese W. und Grover P. N., 1961. Untersuchungen über den Wassergehalt von indischen Bambushalmen. Berichte der Deutschen Botanischen Gesellschaft 74, 105-118. 
1 Lin, J.X., He, X.Q., Hu, Y.X., Kuang, T.Y., Ceulemans, R., 2002. Lignification and lignin

2 heterogeneity for various age classes of bamboo (Phyllostachys pubescens) stems. Physiol. Plant. 114, 3 296-302.

4 Liukkonen, A., 1997. Contact angle of water on paper components: Sessile drops versus 5 environmental scanning electron microscope measurements. Scanning 19, 411-415.

6 Meredith, T.J., 2010. Bamboo Garden. Timber Press, Portland, USA.

7 Ohrnberger, D., 1996. The Bamboos of the World. Bambus Buch.

8 Osorio, L., Trujillo, E., Van Vuure, A.W., Verpoest, I., 2011. Morphological aspects and mechanical 9 properties of single bamboo fibers and flexural characterization of bamboo/epoxy composites. J. 10 Reinf. Plast. Compos. 30, 396-408.

11 Parameswaran, N., Liese, W., 1976. On the fine structure of bamboo fibres. Wood Sci. Technol. 10.

Perremans, D., Trujillo, E., Ivens, J., Van Vuure, A.W., 2018. Effect of discontinuities in bamboo fibre reinforced epoxy composites. Compos. Sci. Technol. 155, 50-57.

Potters, G., Brems, A., Valcke, R., Dewil, R., D'Haese, L., Samson, R., Gielis, J., 2009. Energy Crops in Western Europe: is Bamboo an Acceptable Alternative?, Proc. 8th World Bamboo Congress Thailand, pp. 22-34.

Potters, G., Schutte, F., Van Goethem, D., De Nollin, S., Samson, R., Gielis, J., 2013. Bamboo as a Crop in Western Europe a SWOT analysis, Proc. Ist IS on Genetic Resources of Bamboos and Palms and IIIrd IS on Ornamental Palms, pp. 89-96.

Royal Meteorological Institute (RMI), Accessed in 2016-2017. Current climate Belgium.

Shchukarev, A., Sundberg, B., Mellerowicz, E., Persson, P., 2002. XPS study of living tree. Surf. Interface Anal. 34, 284-288.

Sweygers, N., Somers, M.H., Appels, L., 2018. Optimization of hydrothermal conversion of bamboo (Phyllostachys aureosulcata) to levulinic acid via response surface methodology. J. Environ. Manage 219, 95-102.

Toussaint, A.F., Luner, P., 1993. The wetting properties of graftedcellulose films. J. Adhes. Sci. Technol. 7, 635-648.

Van Goethem, D., 2013. Growth and ecophysiological characterisation of a Phyllostachys humilis bamboo plantation in Ireland, Department of Bioscience Engineering. PhD thesis, University of Antwerp, Belgium, p. 141. Mitigation. International Network for Bamboo and Rattan (INBAR). 
1 Table 1 Size and total weight of the fresh plant, at 18 months of age, averaged for 3 harvested culms. DBH 2 being the diameter at breast height and the total biomass includes culm, leaves and branches. For each species 3 three different culms were measured, $\mathrm{n}=3$, for which the standard deviation was calculated.

\begin{tabular}{lllll}
\hline Species & $\begin{array}{l}\text { Culm height } \\
(\mathrm{m})\end{array}$ & $\mathrm{DBH}(\mathrm{cm})$ & $\begin{array}{l}\text { Basal wall } \\
\text { thickness }(\mathrm{mm})\end{array}$ & Total weight $(\mathrm{kg})$ \\
\hline P. nigra Boryana & $7.7 \pm 0.9$ & $3.8 \pm 0.1$ & $7.2 \pm 0.8^{*}$ & $7.7 \pm 1.0$ \\
$P$. aureosulcata Spectabilis & $7.3 \pm 1.5$ & $3.9 \pm 0.2$ & $7.3 \pm 2.0$ & $2.4 \pm 0.7$ \\
$P$. vivax & $11.7 \pm 1.2$ & $7.4 \pm 0.8$ & $10.7 \pm 1.9$ & $8.0 \pm 2.5$ \\
$P$. vivax McClure Jiantonging & $10.4 \pm 0.8$ & $6.2 \pm 0.3$ & $10.8 \pm 0.4$ & $5.2 \pm 1.6$ \\
\hline
\end{tabular}

*Average thickness recorded from the PNB culms harvested on 07/2017

6 Table 2 Average internodal morphology for the internodes from the middle segment of the culm, considered 7 suitable for fibre extraction. For each species three different culms were measured, $n=3$, for which the standard 8 deviation was calculated.

\begin{tabular}{llll}
\hline Species & Nr of internodes & Internodal length $(\mathrm{cm})$ & Outer diameter $(\mathrm{cm})$ \\
\hline PNB & 10 & $32.0 \pm 3.2$ & $3.6 \pm 0.3$ \\
PAS & 11 & $33.6 \pm 6.6$ & $3.7 \pm 0.3$ \\
PV & 25 & $35.2 \pm 4.4$ & $5.7 \pm 1.5$ \\
PVMJ & 20 & $36.5 \pm 4.9$ & $5.1 \pm 1.0$ \\
\hline
\end{tabular}


1 Table 3 coefficients of the linear fit for the linear region (internode 10-25/35): wall thickness $(\mathrm{mm})=\mathrm{a}^{*}$ outer 2 diameter $(\mathrm{cm})+\mathrm{b}$

\begin{tabular}{lll}
\hline Species & Coefficients \\
& $\mathrm{a}$ & $\mathrm{b}$ \\
\hline PNB & 0.752 & 1.363 \\
PAS & 0.906 & 0.415 \\
PV & 0.605 & 0.900 \\
PVMJ & 0.493 & 1.086 \\
\hline
\end{tabular}

3

4 Table 4 Overview of the density (in fully dry state) and areal fibre bundle fraction for the considered species.

\begin{tabular}{lll}
\hline Species & $\rho_{\mathrm{f}}\left(\mathrm{g} / \mathrm{cm}^{3}\right)$ & $\begin{array}{l}\text { Areal fibre bundle } \\
\text { fraction }(\%)\end{array}$ \\
\hline PNB & 1.48 & 25 \\
PAS & 1.43 & 28 \\
PV & 1.44 & 28 \\
PVMJ & 1.47 & 26 \\
\hline
\end{tabular}

5

6 
1 Table 5 Chemical composition of the fibres used in this study compared to literature for GAK [28]. Experiments

2 were conducted in threefold, standard deviation is given.

\begin{tabular}{llllll}
\hline Species & Cellulose $(\%)$ & Hemicellulose $(\%)$ & Lignin $(\%)$ & Extractives $(\mathrm{g} / 100 \mathrm{~g})$ & Ash $(\mathrm{g} / 100 \mathrm{~g})$ \\
\hline PNB & $51.3 \pm 0.3$ & $16.2 \pm 0.2$ & $32.6 \pm 0.8$ & $5.4 \pm 0.4$ & $1.0 \pm 1.1$ \\
PAS & $52.3 \pm 0.5$ & $12.0 \pm 0.8$ & $35.7 \pm 1.2$ & $14.7 \pm 0.4$ & $1.2 \pm 0.0$ \\
PV & $56.8 \pm 0.5$ & $12.1 \pm 1.0$ & $31.1 \pm 0.7$ & $9.6 \pm 0.8$ & $1.8 \pm 0.0$ \\
PVMJ & $54.7 \pm 0.3$ & $14.4 \pm 0.7$ & $31.0 \pm 0.7$ & $8.3 \pm 0.3$ & $0.3 \pm 0.1$ \\
GAK [25] & $54.6 \pm 1.2$ & $14.0 \pm 0.3$ & $31.4 \pm 1.0$ & $0.7 \pm 0.5$ & $0.6 \pm 0.1$ \\
\hline
\end{tabular}

3

Table 6 XPS data of relative surface atomic fraction, O/C ratio and decomposition of C1s peaks for technical bamboo fibres (H excluded, 1 fibre tested for each species) compared to XPS data of GAK [31] C1-C4 are shown as percentage of $\mathrm{C}$ content.

\begin{tabular}{|c|c|c|c|c|c|c|c|c|c|}
\hline \multirow[b]{3}{*}{ Species } & \multirow[b]{3}{*}{$\mathrm{C}(\%)$} & \multirow[b]{3}{*}{$\mathrm{O}(\%)$} & \multirow[b]{3}{*}{$\mathrm{N}(\%)$} & \multirow[b]{3}{*}{$\mathrm{Si}(\%)$} & \multirow[b]{3}{*}{$\mathrm{O} / \mathrm{C}$} & \multicolumn{3}{|c|}{ Binding energy $(\mathrm{eV})$} & \multirow{3}{*}{$\begin{array}{l}288.5 \\
\text { C4 (\%) }\end{array}$} \\
\hline & & & & & & 284.8 & 286.3 & 287.2 & \\
\hline & & & & & & $\mathrm{C} 1(\%)$ & $\mathrm{C} 2(\%)$ & $\mathrm{C} 3(\%)$ & \\
\hline & & & & & & $(\mathrm{C}-(\mathrm{C}, \mathrm{H}))$ & $(\mathrm{C}-\mathrm{O})$ & $(\mathrm{C}=\mathrm{O}, \mathrm{O}-\mathrm{C}-\mathrm{O})$ & $(\mathrm{O}-\mathrm{C}=\mathrm{O})$ \\
\hline PNB & 69.52 & 26.48 & 3.21 & 0.27 & 0.38 & 46.45 & 33.47 & 11.61 & 8.47 \\
\hline PAS & 69.64 & 26.68 & 1.98 & 0.54 & 0.38 & 54.47 & 30.43 & 8.44 & 6.66 \\
\hline PV & 70.53 & 24.33 & 4.00 & 0.78 & 0.34 & 55.67 & 26.67 & 8.78 & 8.87 \\
\hline \multirow[t]{3}{*}{ PVMJ } & 66.80 & 30.30 & 2.22 & 0.40 & 0.45 & 43.44 & 34.79 & 13.76 & 8.01 \\
\hline & & & & & & \multicolumn{3}{|c|}{ Binding energy $(\mathrm{eV})$} & \\
\hline & & & & & & 284.8 & 286.3 & 287.2 & 288.5 \\
\hline $\begin{array}{l}\text { GAK } \\
{[31]}\end{array}$ & $\begin{array}{l}74.3 \pm \\
1.5\end{array}$ & $\begin{array}{l}22.9 \pm \\
0.3\end{array}$ & $\begin{array}{l}1.8 \pm \\
0.7\end{array}$ & $\begin{array}{l}0.6 \pm \\
0.4\end{array}$ & $\begin{array}{l}0.3 \pm \\
0.0\end{array}$ & $58.0 \pm 3.1$ & $28.8 \pm 2.3$ & $7.6 \pm 1.3$ & $5.6 \pm 0.4$ \\
\hline
\end{tabular}

7 
1 Table 7 Dynamic advancing contact angles (ultrapure water, $6 \mathrm{~mm}, 1.5 \mathrm{~mm} / \mathrm{min}$ )

\begin{tabular}{llllll}
\hline & \multicolumn{2}{c}{ Species } & & & \\
\cline { 2 - 5 } Specimen number & PNB & PAS & PV & PVMJ & \multicolumn{2}{c}{ Guadua angustifolia Kunth [28] } \\
\cline { 4 - 6 } 1 & & & & Non-treated & Autoclave-treated \\
2 & $66 \pm 7^{\circ}$ & $83 \pm 4^{\circ}$ & $87 \pm 7^{\circ}$ & $62 \pm 4^{\circ}$ & \\
3 & $59 \pm 6^{\circ}$ & $64 \pm 10^{\circ}$ & $73 \pm 7^{\circ}$ & $60 \pm 4^{\circ}$ & \\
4 & $65 \pm 4^{\circ}$ & $76 \pm 4^{\circ}$ & $73 \pm 5^{\circ}$ & $75 \pm 3^{\circ}$ & \\
\hline Average & $70 \pm 3^{\circ}$ & $88 \pm 4^{\circ}$ & $84 \pm 7^{\circ}$ & $73 \pm 6^{\circ}$ & \\
\hline
\end{tabular}

2

3

4 


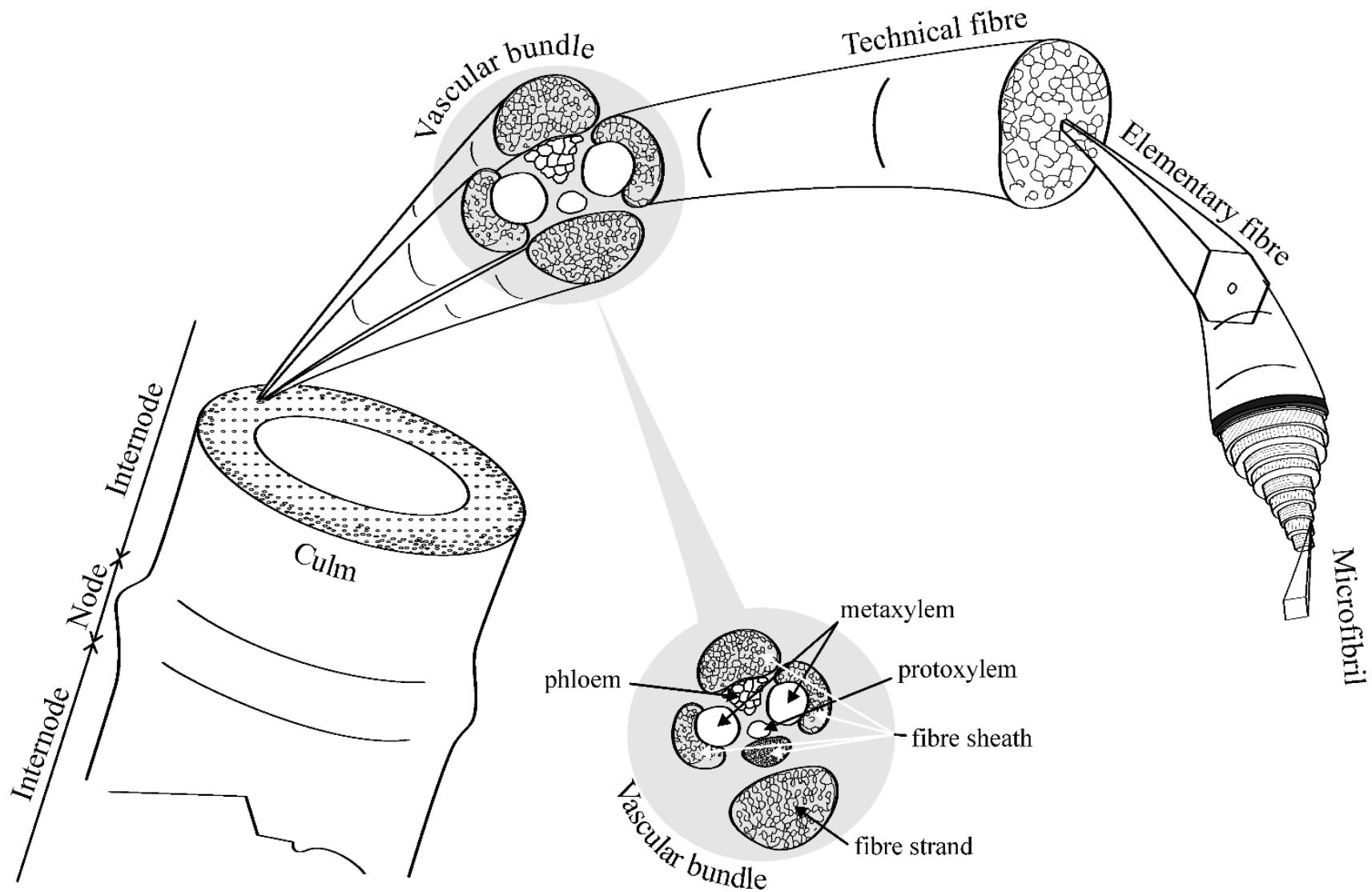

Figure 1 Exploded view of the hierarchical structure of a bamboo plant, from culm to microfibril, incorporating the polylamellate elementary fibre structure according to Parameswaran and Liese [15]. Typical diameter of the technical and elementary fibres are $90-280 \mu \mathrm{m}$ and $10-40 \mu \mathrm{m}$ respectively

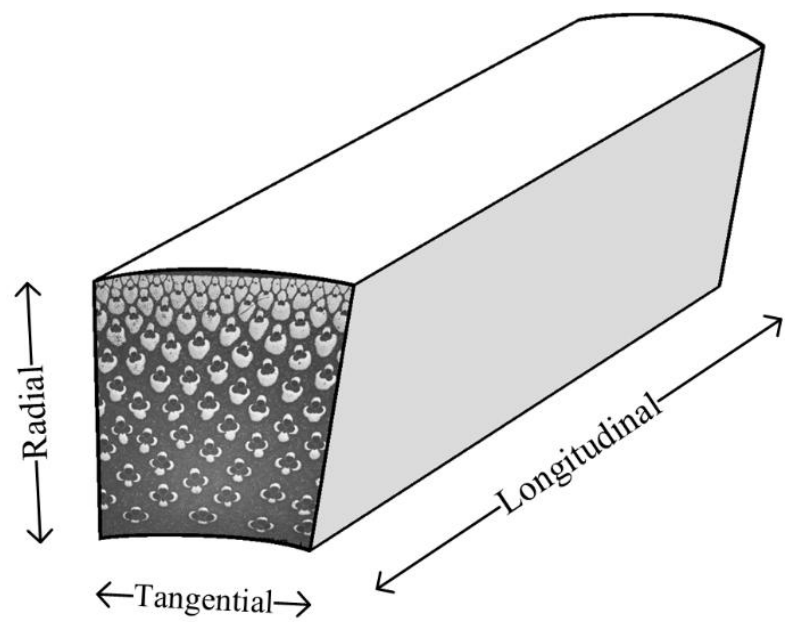

Figure 2 Dimensions of the samples used for the shrinkage study and radial, tangential and longitudinal shrinkage indicated; the longitudinal direction is the fibre direction; the tangential direction is in the direction of the circumference of the culm and the radial direction is the culm wall thickness direction. Dimensions of the beam are $20 \mathrm{x} 4 \mathrm{xt} \mathrm{mm}$ with $\mathrm{t}$ the thickness of the culm wall 


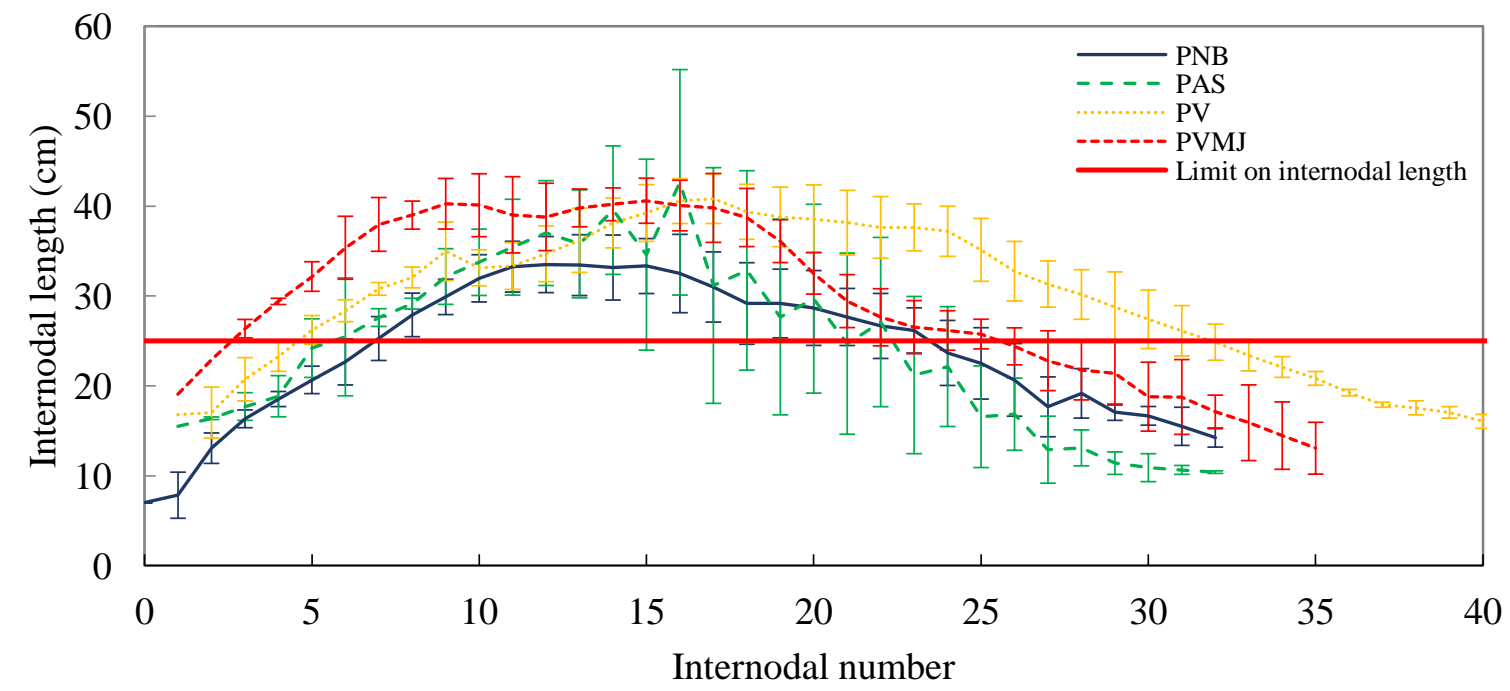

1

2 Figure 3 Internodal length variation along the bamboo culms in function of the internode number, with the limit 3 criterion for fibre extraction at $25 \mathrm{~cm}$ indicated. For each species three different culms were measured, $\mathrm{n}=3$, for 4 which the standard deviation was calculated and is shown.

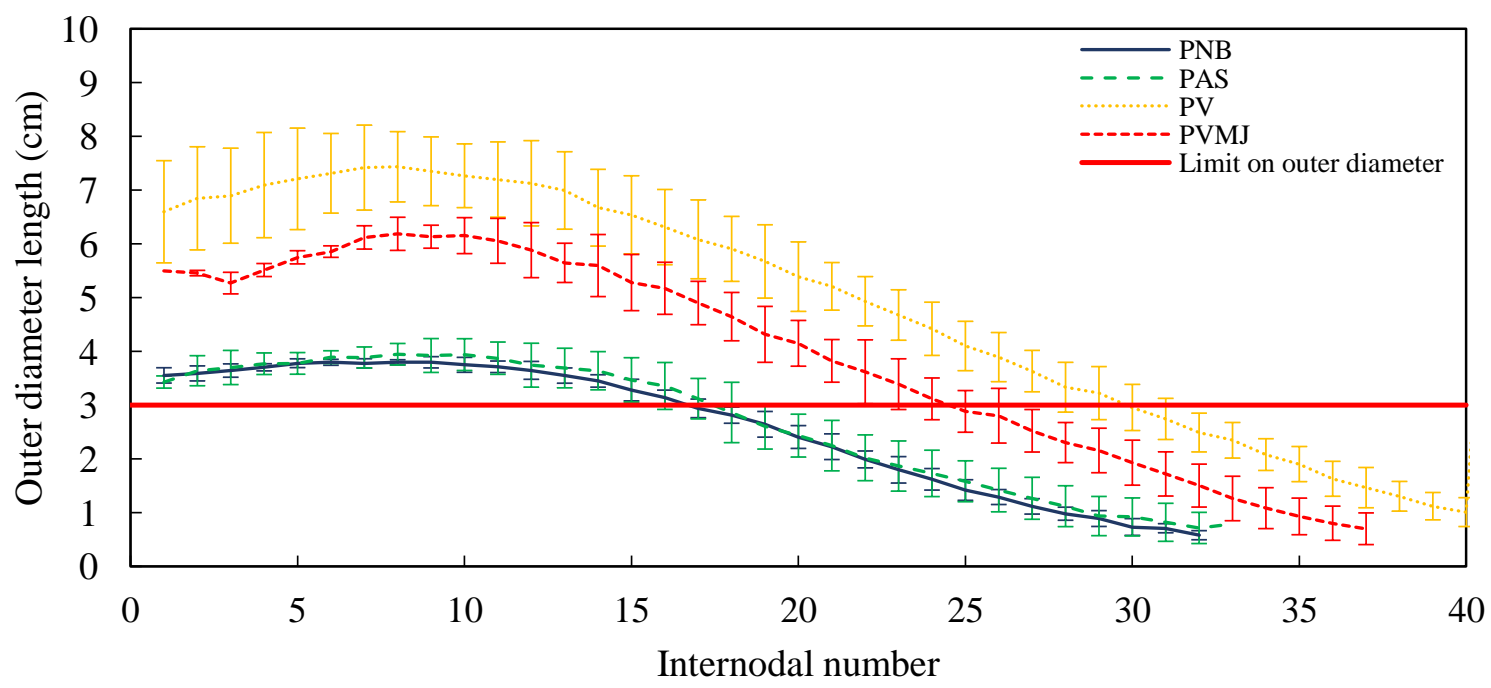

5

Figure 4 Internodal outer diameter variation along the bamboo culms in function of the internode number, with the limit criterion on outer diameter of $3 \mathrm{~cm}$ indicated. For each species three different culms were measured, $\mathrm{n}$ $=3$, for which the standard deviation was calculated and is shown. 


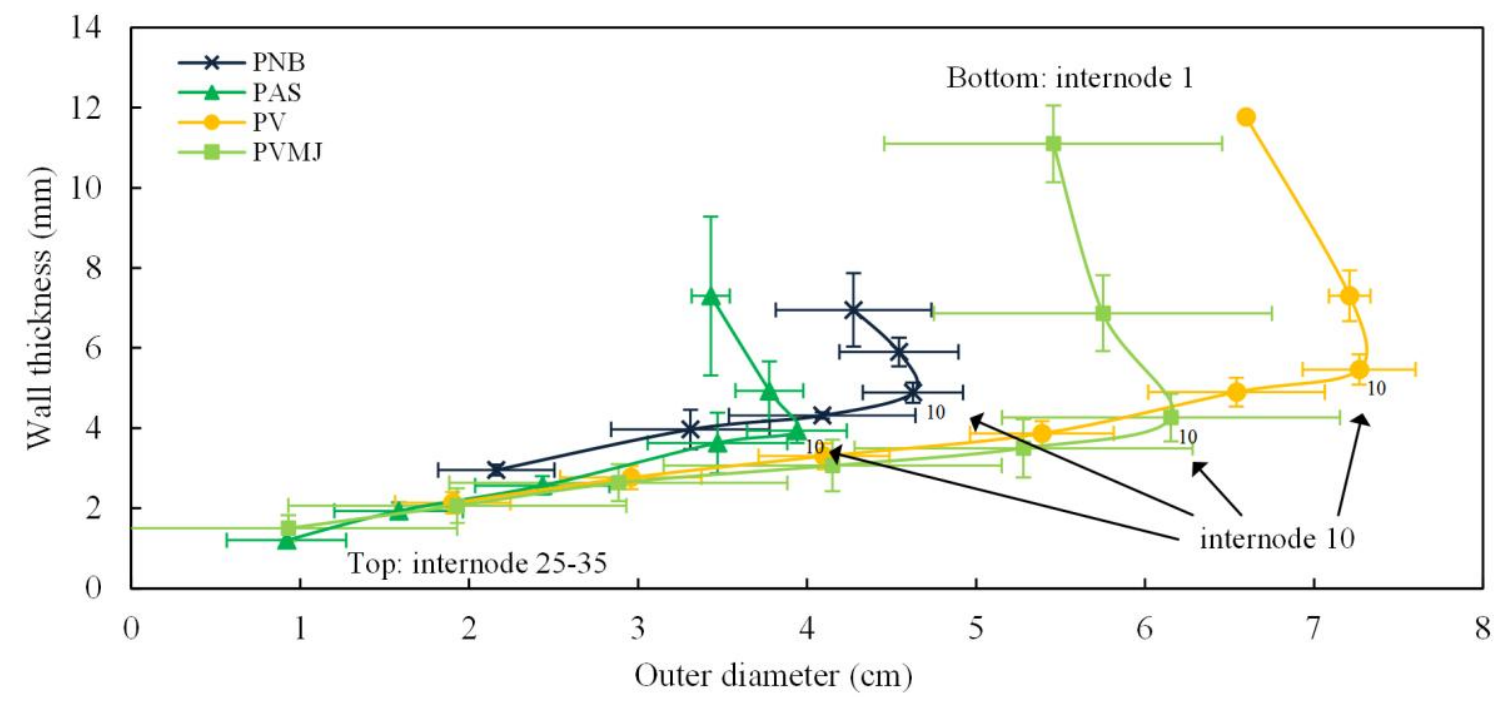

Figure 5 Wall thickness versus the outer diameter of the considered species. For each species three different culms were measured, $n=3$, for which the standard deviation was calculated and is shown. Starting from the bottom: a rapid decline in wall thickness with slightly increasing diameter until the maximum diameter is reached around the 10th internode. From the 10th internode onward, a linear relationship can be found (data till internode 25 for PNB, till 30 for PAS, till 35 for PV and PVMJ). For PNB the outer diameter and wall thickness of the harvest of 07/2017 were used. 
a)

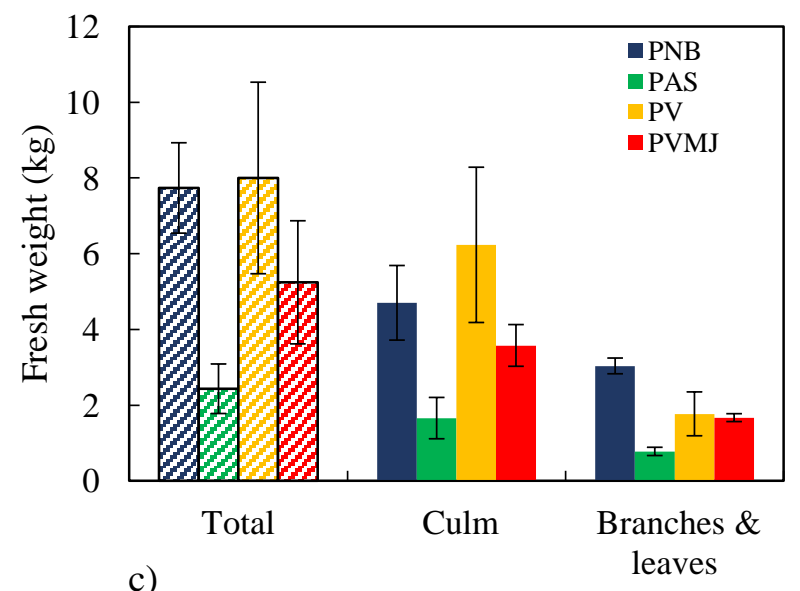

c)

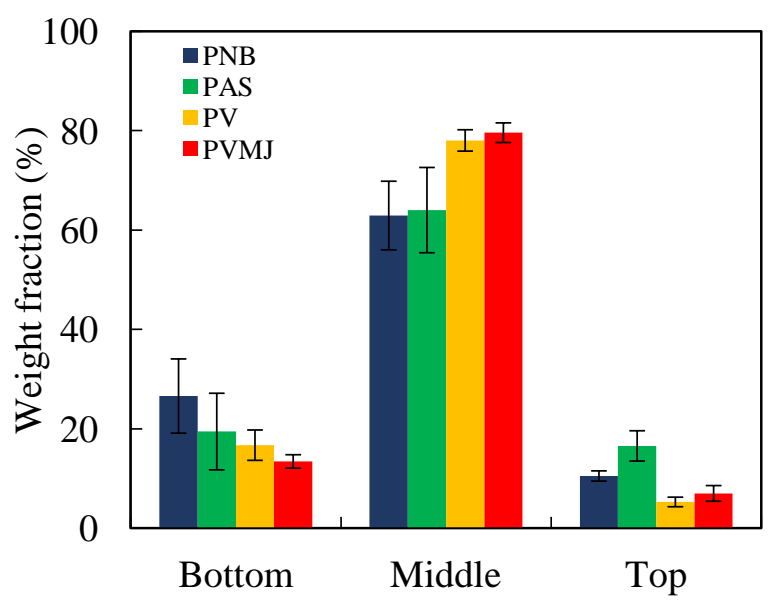

b)

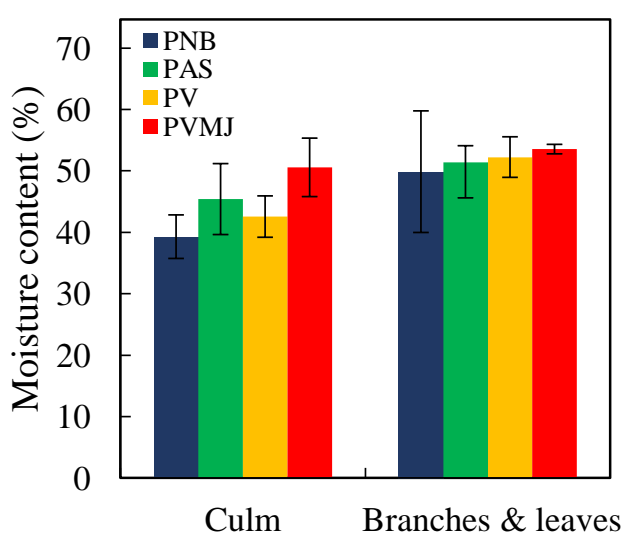

Figure 6 a) The total above ground fresh weight of the harvested bamboo plants divided in culm \& branches and 7 leaves (includes water) b) the water content for the culm and branches \& leaves section c) Weight distribution in 8 the culm, for the bottom, middle and top section. The results are the average of 3 culms $(n=3)$ for each species harvested between 15/09/2016 and 12/10/2016, standard deviation was calculated and is shown. 
a)
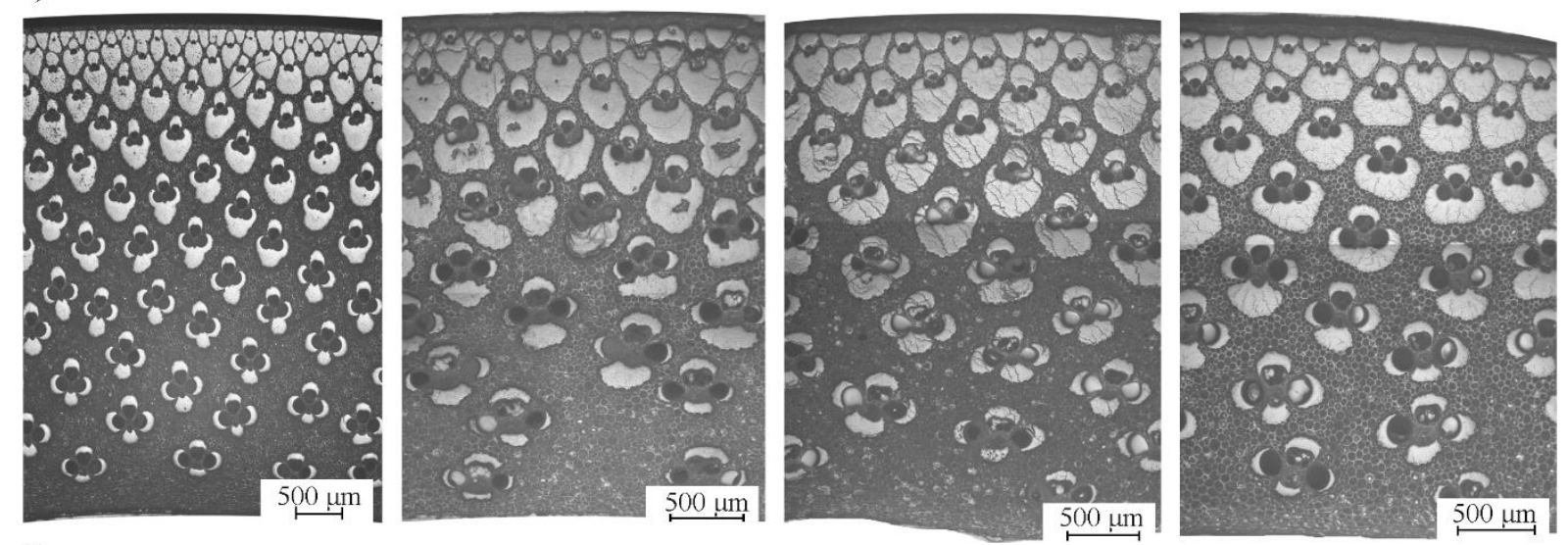

b)

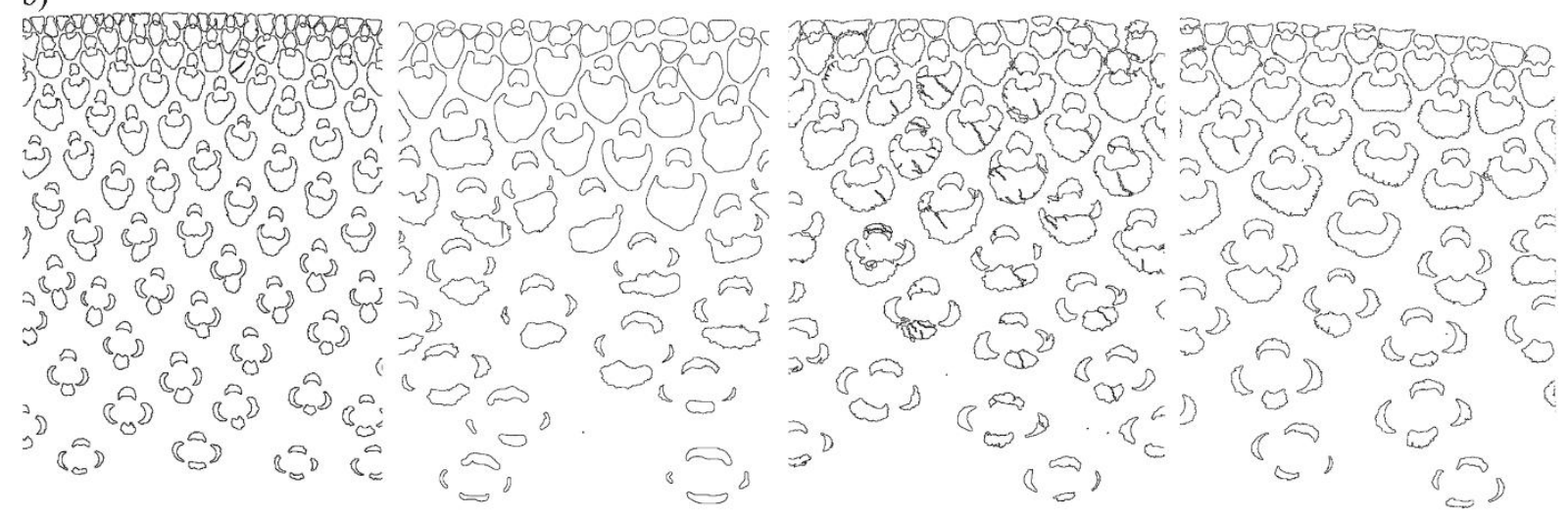

Figure 7 a) Cross sectional views of the considered species from left to right: PNB, PAS, PV, PVMJ; the images were used for the analysis of the fibre areal bundle fraction $b$ ) the contour images were determined via ImageJ
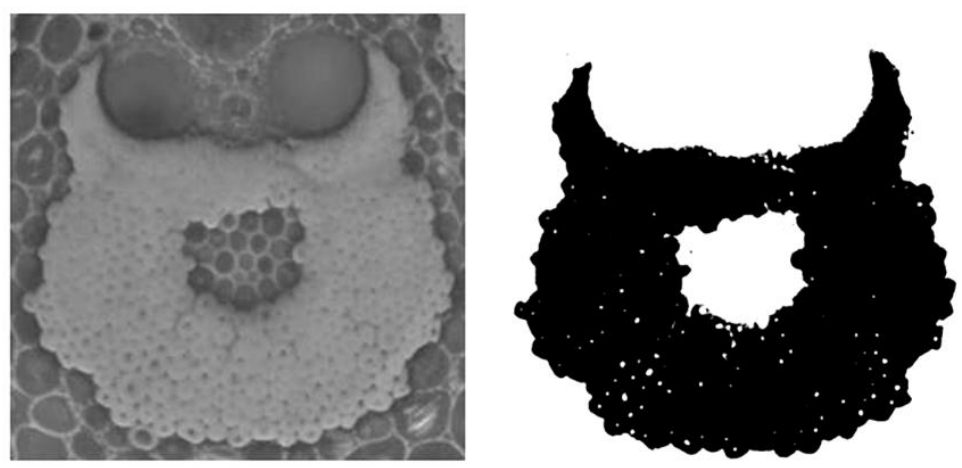

5

Figure 8 Zoom of a fibre cap with parenchyma inside of the PAS species, and an image where the area with only fibre cells is indicated in black 

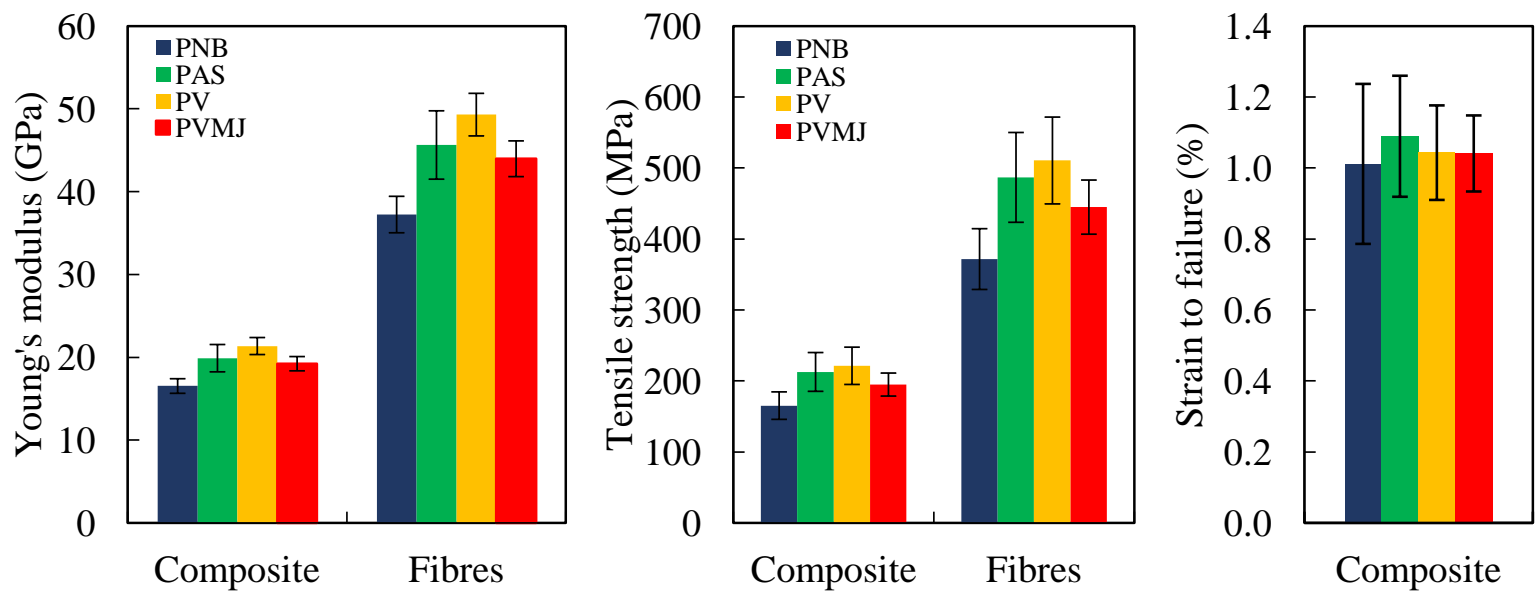

2

Figure 9 Overview of the mechanical properties the 4 considered species. Composite properties are normalised to a $V_{f}$ of $40 \%$. PNB is further analysed in the seasonal study.
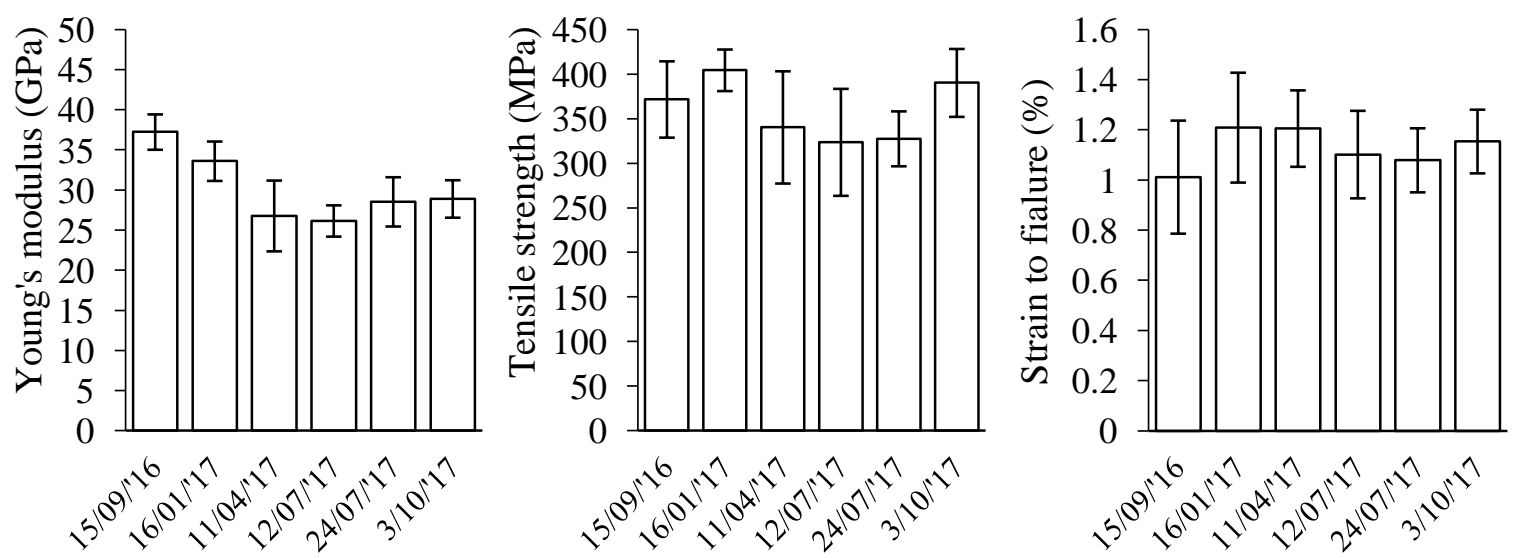

7

8 Figure 10 Back calculated fibre properties in function of the different seasons for the PNB species 


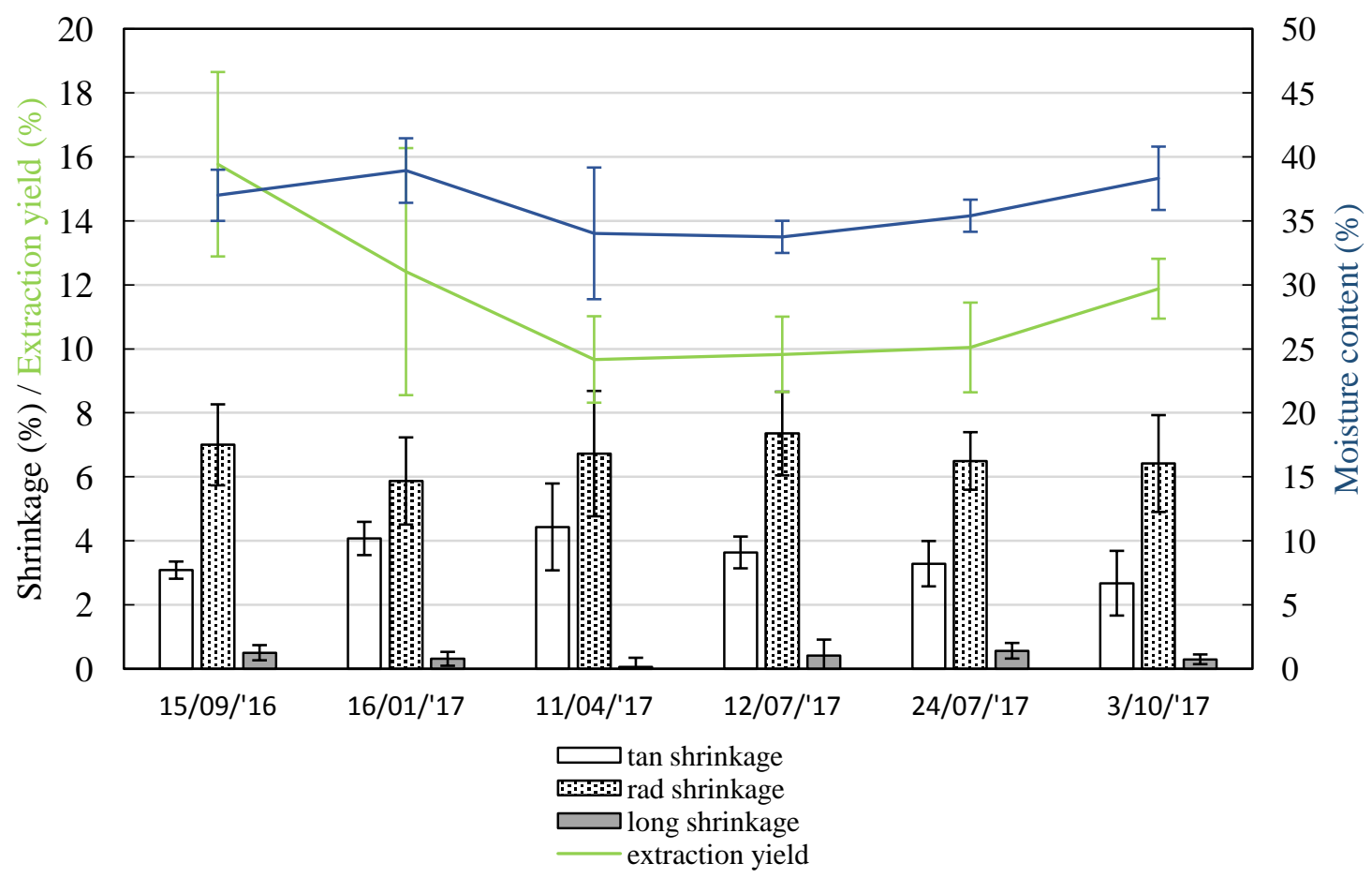

2 Figure 11 Results of the shrinkage, extraction yield and moisture content of the bamboo culm for the PNB species. For each species three different culms were measured, $n=3$. The standard deviation was calculated and is shown.

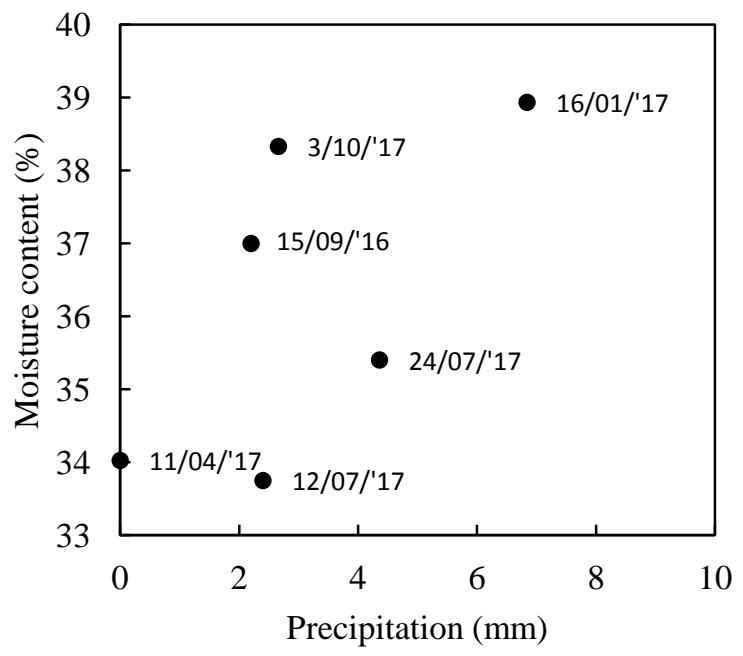

5

6 Figure 12 The culm moisture content as function of the average precipitation of 5 days prior to harvesting [29] 




2 Figure 13 Correlation between $\mathrm{C} 1 / \mathrm{C}$ and $\mathrm{O} / \mathrm{C}$ ratios determined by XPS analysis of the studied technical 3 bamboo fibre surfaces, compared to fibres of the GAK [31], Protobind 1000 Granit lignin [28]

4

5 